\title{
DESREGULADORES ENDÓCRINOS NO MEIO AMBIENTE: EFEITOS E CONSEQÜÊNCIAS
}

\section{Daniele Maia Bila e Márcia Dezotti*}

Coordenação dos Programas de Pós-graduação de Engenharia, Universidade Federal do Rio de Janeiro, CP 68501, 21945-970 Rio de Janeiro - RJ, Brasil

Recebido em 21/3/06; aceito em 21/7/06; publicado na web em 22/2/07

\begin{abstract}
ENDOCRINE DISRUPTERS IN THE ENVIRONMENT: PART 1 - EFFECTS AND CONSEQUENCES. There is an increasing interest in micropollutants in the environment that can interfere with the endocrine system, affecting health, growth and reproduction of animals and humans. These substances are known as Endocrine Disrupting Chemicals (EDCs) and can be found in domestic sewage, domestic wastewater treatment plant effluents, and in natural and potable waters. There are numerous chemicals classified as EDCs, such as pesticides, chemicals used and produced by chemical industries and natural and synthetic estrogens. EDCs can be related to the increase of the incidence of anomalies in the reproductive system of animals, cancer in humans and reduction of the masculine fertility.
\end{abstract}

Keywords: Endocrine Disrupting Chemicals; environment; human health.

\section{INTRODUÇÃO}

Atualmente, um dos tópicos mais relevantes na química ambiental é a qualidade da água. A preocupação com micropoluentes - poluentes que estão presentes no meio ambiente em concentrações na ordem de $\mu \mathrm{g} \mathrm{L}^{-1}$ e ng $\mathrm{L}^{-1}$ - tem aumentado expressivamente nos últimos anos. Fármacos, desreguladores endócrinos e poluentes orgânicos persistentes (POP) são classes de substâncias muito investigadas devido, principalmente, aos seus efeitos no meio ambiente. Uma grande preocupação relacionada a essas classes de substâncias é que podem produzir efeitos adversos aos organismos expostos em concentrações realmente muito baixas.

Há grande interesse científico em um grupo de substâncias químicas presentes no meio ambiente que podem interferir no sistema endócrino de humanos e outros animais e, com isso, afetar a saúde, o crescimento e a reprodução. Essas substâncias são conhecidas como Desreguladores Endócrinos.

Em seres humanos e animais a desregulação endócrina é um mecanismo de efeito relacionado ao funcionamento do sistema endócrino. Segundo a União Européia (UE), os desreguladores endócrinos podem ${ }^{1}$ : danificar diretamente um órgão endócrino; alterar diretamente a função de um órgão endócrino; interagir com um receptor de hormônios ou, alterar o metabolismo de um hormônio em um órgão endócrino.

A origem da hipótese da ação dos desreguladores endócrinos deve-se a acontecimentos importantes, tais como, o aparecimento de câncer no sistema reprodutivo de filhas de mulheres que usaram DES (dietilestilbestrol) na gravidez, entre os anos de 1940 a 1970² anomalias no sistema reprodutivo observadas em jacarés que habitavam um lago na Flórida contaminado com o pesticida DDT e seu metabólito $\mathrm{DDE}^{3}$ e um estudo na Dinamarca que relata o declínio da qualidade do sêmen de homens durante aproximadamente 50 anos, entre os anos de 1938 e $1990^{4}$.

Atualmente, as maiores preocupações em relação à exposição de humanos e outros animais aos desreguladores endócrinos são: se essas substâncias podem produzir efeitos tóxicos em baixas concentrações; quais substâncias estão associadas aos efeitos tóxicos a bai-

*e-mail: mdezotti@peq.coppe.ufrj.br xas concentrações; se essas substâncias estão presentes em concentrações ambientalmente relevantes que possam ser uma ameaça à saúde de humanos e animais; se existe uma concentração limiar abaixo da qual essas substâncias químicas podem ser consideradas como seguras; se os novos tipos de ensaios, usados para prever os efeitos causados em organismos expostos, podem realmente fornecer ferramentas para o entendimento do mecanismo de ação dessas substâncias e, se esses ensaios podem ser facilmente usados em larga escala para monitorar seus efeitos no meio ambiente.

Várias são as substâncias que possuem a capacidade de afetar o sistema endócrino, tais como, substâncias sintéticas (alquilfenóis, pesticidas, ftalatos, policlorados de bifenilas (PCD), bisfenol A, substâncias farmacêuticas, entre outras) e substâncias naturais (estrogênios naturais e fitoestrogênios).

Devido à dificuldade de identificação desses micropoluentes no meio ambiente, muitos métodos analíticos foram desenvolvidos para detectar e quantificar essas substâncias em matrizes ambientais complexas, tais como águas superficiais e subterrâneas, esgoto doméstico, efluentes de ETE, sedimentos marinhos, solo e lodo biológico. Adicionalmente, a necessidade de se conhecer os efeitos potenciais dos desreguladores endócrinos tem conduzido a uma demanda por métodos de ensaios in vitro e in vivo para identificar os efeitos biológicos de uma grande variedade de substâncias naturais e sintéticas presentes no meio ambiente.

O comportamento dos desreguladores endócrinos nas ETE, solo e sedimentos marinhos tem sido investigado, bem como seu transporte e destino no meio ambiente ${ }^{5-12}$. O conhecimento do destino e dos processos de transporte desses poluentes no meio ambiente é essencial para avaliar seus impactos potenciais no solo e águas naturais.

Vários consórcios foram criados em todo o mundo com o objetivo de avaliar a complexa situação dos desreguladores endócrinos, e são exemplos da crescente preocupação mundial com essas substâncias. Diversos assuntos são abordados e investigados, tais como o monitoramento de substâncias estrogênicas em amostras de águas naturais (ARCEM - "Austrian Research Cooperation on Endocrine Modulators"); a validação dos métodos de ensaios que determinam as substâncias com potencial de desregulação endócrina (EDSTAC - "Endocrine Disruptor Screening and Testing Advisory Committee", EDTA - "Endocrine Disrupter Testing and Assessment 
Task Force"); a identificação e caracterização de todos os efeitos relatados (EDSP - "Environmental Disruptor Screening Program" e programa COMPREHEND - "Community Programme of Research on Endocrine Disrupters and Environmental Hormones"; CSTEE - "Committee on Toxicity, Ecotoxicity and the Environment"); organização do conhecimento científico disponível sobre os desreguladores endócrinos (SPEED'98/JEA "Exogenous Endocrine Disrupting Chemical Task Force" e COM - "Community Strategy for Endocrine Disrupters"), entre outros.

A presença de desreguladores endócrinos em estações de tratamento de esgoto e em fontes de água potável demonstra que é necessária uma avaliação dos processos de tratamento envolvidos com respeito à eficiência de remoção dessas substâncias. Os processos oxidativos $\left(\mathrm{O}_{3} / \mathrm{H}_{2} \mathrm{O}_{2}\right.$, fotocatálise com $\left.\mathrm{TiO}_{2}, \mathrm{H}_{2} \mathrm{O}_{2} / \mathrm{UV}\right)$ e a ozonização são tecnologias bastante promissoras para a oxidação dessas substâncias no tratamento de água e esgoto doméstico ${ }^{13-15}$. Outros tratamentos também foram investigados, tais como, cloração, filtração em carvão ativado, processos com membranas de nanofiltração (NF) e osmose reversa (OR), entre outros.

No entanto, o conhecimento dos subprodutos desses compostos, bem como a avaliação dos seus efeitos são extremamente importantes. O foco principal da eliminação dos desreguladores endócrinos do meio ambiente deve levar em conta, principalmente, a remoção de sua atividade biológica.

\section{DESREGULADORES ENDÓCRINOS (DE)}

As substâncias denominadas desreguladores endócrinos são uma categoria recente de poluentes ambientais que interferem nas funções do sistema endócrino. Essas substâncias são encontradas no meio ambiente em concentrações da ordem de $\mu \mathrm{g} \mathrm{L}^{-1}$ e ng $\mathrm{L}^{-1}$ e são suspeitas de causarem efeitos adversos à saúde humana e animal.

Alguns efeitos citados na literatura, tais como diminuição na eclosão de ovos de pássaros, peixes e tartarugas; feminização de peixes machos; problemas no sistema reprodutivo em peixes, répteis, pássaros e mamíferos e, alterações no sistema imunológico de mamíferos marinhos, têm sido associados à exposição de espécies de animais aos desreguladores endócrinos. Em alguns casos esses efeitos podem conduzir ao declínio da população. Em seres humanos esses efeitos incluem a redução da quantidade de esperma, o aumento da incidência de câncer de mama, de testículo e de próstata e, a endometriose.

Os DE abrangem uma grande faixa de classe de substâncias com estruturas distintas, incluindo hormônios sintéticos e naturais, substâncias naturais e uma grande quantidade de substâncias sintéticas.

\section{DEFINIÇÃO - O QUE É UM DESREGULADOR ENDÓCRINO?}

Algumas definições são propostas para essas substâncias, denominadas em inglês "Endocrine Disrupting Chemicals" (EDCs). Alguns autores entendem que são considerados "endocrine disrupting chemicals" somente as substâncias que interagem com sítios receptores de hormônios, enquanto outros entendem como qualquer substância que cause desequilíbrio, interferência ou alteração no sistema endócrino, independentemente se atua diretamente no sítio receptor ou não.

De acordo com a "Environmental Protection Agency" (EPA), um desregulador endócrino é definido como um ${ }^{16}$ "agente exógeno que interfere com síntese, secreção, transporte, ligação, ação ou eliminação de hormônio natural no corpo que são responsáveis pela manutenção, reprodução, desenvolvimento e/ou comportamento dos organismos".
O Programa Internacional de Segurança Química (IPCS), em conjunto com o Japão, os EUA, o Canadá, a OECD e a União Européia, adotou a seguinte definição ${ }^{17}$ : "Um desregulador endócrino é uma substância ou um composto exógeno que altera uma ou várias funções do sistema endócrino e tem, conseqüentemente, efeitos adversos sobre a saúde num organismo intacto, sua descendência, ou (sub) populações".

A tradução do termo "endocrine disrupting chemicals" também não é simples, sendo que existem cinco possíveis traduções: perturbadores endócrinos, interferentes endócrinos, desreguladores endócrinos, disruptores endócrinos e interferentes hormonais. Os termos mais usados são perturbadores endócrinos e desreguladores endócrinos.

Mesmos os termos em inglês geram dúvidas em relação aos seus efeitos e a existência de vários termos confirma isso. Na literatura podem ser encontrados "endocrine disrupting", "endocrine modulator", "environmental estrogen", sendo o primeiro termo o mais usado. Segundo"o "American Council on Science and Health" $(\mathrm{ACSH})^{18}$, o termo "endocrine disrupting" sugestiona que os efeitos de tais substâncias são negativos, mas é também concebível que a exposição a essas substâncias hormonalmente ativas pode conduzir a resultados benéficos. Já, segundo a ACHS, as substâncias "endocrine modulator" referem-se às substâncias químicas industriais, tais como, policlorados de bifenilas e pesticidas.

Existem ainda outras definições para as substâncias estrogênicas presentes no meio ambiente. Freqüentemente, são referidos como estrogênios ambientais, estrogênios exógenos ou exoestrogênios. Exoestrogênios são diversos grupos de substâncias que não necessariamente apresentam alguma semelhança com a estrutura química do $17 \beta$-estradiol, mas causam respostas antagônicas e agônicas, possivelmente através de mecanismos de ação via receptores hormonais. A atividade agonista é a capacidade de uma substância acoplar-se ao receptor de hormônios esteróides e elucidar uma resposta. Em contrapartida, a atividade antagonista é a habilidade de uma substância acoplar-se ao receptor de estrogênio e bloquear a ação do ligante natural (estrogênio) e, assim, sua resposta não será elucidada. Essas substâncias podem ser identificadas por sua capacidade de ligar-se ao receptor de estrogênios (RE) e induzir ou atenuar uma resposta hormonal ${ }^{19}$.

Os estrogênios endógenos são produzidos naturalmente pelo corpo humano, como por ex., o $17 \beta$-estradiol e a estrona. A Figura 1 apresenta as estruturas químicas de alguns estrogênios naturais e sintéticos. As substâncias sintéticas com atividade estrogênica também são denominadas de xenoestrogênios por alguns autores ${ }^{20-23}$. Os termos estrogênios ambientais ou eco-estrogênios também geram controvérsias no meio científico, pois omitem a possibilidade de substâncias que não sejam estrogênicas, como por ex., andrógenos (hormônios masculinos), anti-andrógenos e antiestrogênicas, poderem afetar o sistema endócrino. Outros autores usam o termo substância estrogênica para quaisquer substâncias que interagem com receptores de hormônios esteróides, sendo ele receptor de estrogênio ou não.
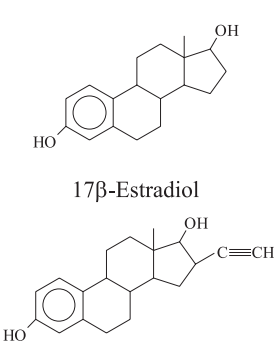

$17 \alpha$-Etinilestradiol

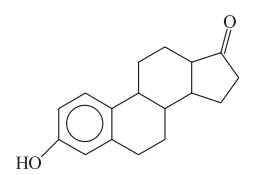

Estrona

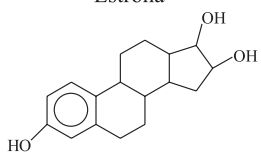

Estriol
Figura 1. Estrutura química de estrogênios naturais e sintéticos 
Outras definições também geram confusões, que alguns autores tentam esclarecer ${ }^{24}$. Substância estrogênica refere-se à substância cujo efeito se dá através do receptor de estrogênio, iniciando uma cascata de efeitos específicos no tecido/célula similar aos iniciados pelo $17 \beta$-estradiol. Os termos anti-andrógeno e antiestrogênico não são especificamente limitados às interações através dos RA e RE, respectivamente. Anti-hormônios podem atuar via receptores de hormônios esteróides, inibição da síntese dos hormônios esteróides, diminuição da biodisponibilidade pela redução da quantidade de hormônios livres no sangue, aumento do metabolismo dos hormônios que conduz a uma redução dos níveis desses hormônios no sangue, entre outros mecanismos ${ }^{24}$.

Os chamados "endocrine disrupting chemicals" originalmente foram relacionados com substâncias que mimetizam a ação dos estrogênios naturais. Porém, com a descoberta de outros mecanismos de ação, gerou-se uma confusão na nomenclatura. Com isso, o que se percebe é que a comunidade científica ainda não entrou em consenso sobre qual a nomenclatura correta que deve ser empregada para essa classe de substâncias, no que se refere a todos os seus efeitos causados.

Neste trabalho, será usado o termo Desregulador Endócrino (DE), sendo esta a nomenclatura usada pela União Européia nos textos em português.

\section{HISTÓRICO E ESTADO ATUAL DO CONHECIMENTO}

A hipótese de que substâncias químicas presentes no meio ambiente podem causar uma resposta biológica nos organismos expostos não é nova. Os efeitos causados ao sistema endócrino de animais de laboratório por substâncias estrogênicas foram primeiramente evidenciados nos anos 1900 por alguns pesquisadores ${ }^{25,26}$. Porém, recentemente este assunto emergiu com maior interesse na comunidade científica, devido ao aumento na detecção de anomalias na saúde humana e de outros animais, que podem estar relacionadas à ação dos desreguladores endócrinos.

O caso mais famoso sobre os desreguladores endócrinos é o do DDT e seus subprodutos, um pesticida muito utilizado em todo mundo durante as décadas de 50 e 60, e que ainda hoje é usado em alguns países. Estudos mostraram que o DDT é persistente no meio ambiente, apresenta atividade estrogênica e pode afetar o sistema reprodutivo de mamíferos e pássaros ${ }^{16}$. Exemplo disso são as anomalias detectadas no sistema reprodutivo de jacarés em vários lagos da Flórida contaminados com DDT ${ }^{3}$. Segundo $\mathrm{Safe}^{27}$ em 1962, Rachel Carson publicou o livro "Silent Spring", que foi um dos primeiros relatos sobre a ligação da presença do pesticida DDT no meio ambiente e o declínio na população de algumas espécies de animais.

Uma fase bastante crítica à exposição de desreguladores endócrinos é a do desenvolvimento fetal; o exemplo mais claro dos efeitos causados em fetos foi o uso do potente estrogênio sintético DES em mulheres grávidas, entre os anos de 1948 a 1970. Este fármaco era prescrito por médicos para evitar abortos e promover o crescimento fetal. Mais tarde descobriu-se que as crianças nascidas de mulheres que fizeram uso desse medicamento, quando atingiam a puberdade apresentaram disfunção no sistema reprodutivo, gravidez anormal, redução na fertilidade, desordem no sistema imunológico e muitas desenvolveram câncer vaginal ${ }^{2,28}$. Recentes estudos sugerem que substâncias estrogênicas, como o DES, podem apresentar efeitos duradouros no sistema reprodutivo em humanos expostos in utero $^{16}$. Os efeitos relatados a curto, médio e longo prazo do DES têm servido como exemplo e de comparação para os efeitos da exposição de seres humanos aos desreguladores endócrinos. Este é o primeiro exemplo documentado de uma substância química que, quando administrada à mãe, pode causar câncer na filha.
Em 1993, Colborn et al. ${ }^{28}$ publicaram uma revisão sobre anomalias em pássaros e peixes associadas à exposição de subprodutos industriais (dioxinas e bifenilas policloradas) e pesticidas (DDT), em áreas como os Grandes Lagos na América do Norte. Também relataram que a exposição humana ao DES ocorrida no passado serve como um modelo para a exposição a substâncias estrogênicas durante o estágio prematuro da vida.

Em 1996, Colborn e colaboradores publicaram o livro "Our Stolen" que também relatou a possibilidade de efeitos no sistema endócrino de humanos e outros animais serem causados por substâncias presentes no meio ambiente. Este livro faz um levantamento detalhado de problemas ambientais causados por substâncias químicas que, mesmo em baixas concentrações, podem causar efeitos adversos ao sistema reprodutivo de animais.

No Brasil, recentemente foram relatados alguns efeitos relacionados à exposição de desreguladores endócrinos no meio ambiente. Fernandez et al. ${ }^{29}$ relataram a exposição de organismos marinhos a compostos orgânicos contendo estanho, o tributilestanho (TBT) e o trifenilestanho (TPT), no litoral do Brasil (Rio de Janeiro, Fortaleza) e o desenvolvimento de caracteres sexuais masculinos em fêmeas de moluscos, fenômeno conhecido como "imposex". Koifman et $a l .{ }^{30}$ apresentaram os resultados de um estudo epidemiológico, que relaciona a exposição a pesticidas durante os anos 80 e distúrbios reprodutivos, tais como, câncer de mama, ovário e próstata, taxas de avaliação de esperma, observados nos anos 90 em estados brasileiros. Torres et al. ${ }^{31}$ investigaram a concentração e destino de pesticidas, bifenilas policloradas (PCB) e hidrocarbonetos aromáticos policíclicos (HAP) na bacia hidrográfica Paraíba do Sul/Guandu, importantes reservatórios de água usados no abastecimento da população. Os resultados indicaram que poluentes industriais, principalmente os HAP, foram encontrados na água e em sedimentos marinhos.

\section{ESTRATÉGIAS INTERNACIONAIS PARA AVALIAR O PROBLEMA DOS DE}

Nas últimas duas décadas, houve um aumento da preocupação na comunidade científica dos debates públicos e da atenção da mídia em relação aos possíveis efeitos danosos causados aos humanos e outros animais pela exposição a substâncias químicas presentes no meio ambiente que têm o potencial de afetar o sistema endócrino.

Para esclarecer, desenvolver estratégias e solucionar o problema dos desreguladores endócrinos, várias organizações governamentais e não governamentais, como, União Européia (UE), Agência de Proteção Ambiental dos Estados Unidos (EPA), Organização Mundial de Saúde (OMS), Programa Internacional de Segurança Química (IPCS) e a Organização para a Cooperação e Desenvolvimento Econômico (OCDE), investigam a questão dos desreguladores endócrinos. Alguns estudos são apresentados na Tabela 1.

\section{SUBSTÂNCIAS CLASSIFICADAS COMO DESREGULADORES ENDÓCRINOS}

Com base em informações disponíveis na literatura foram elaboradoas, por várias organizações mundiais, listas de substâncias químicas suspeitas de causar desregulação do sistema endócrino $^{2,10,17,40}$. Contudo, ainda são necessários mais dados científicos para uma investigação mais profunda a fim de identificar os critérios de seleção utilizados para agrupar as substâncias nestas listas. Para tal, a UE lançou um estudo que é o primeiro passo para estabelecimento de uma lista de substâncias para a futura avaliação do seu papel na desregulação endócrina. 
Tabela 1. Seminários, comitês e relatórios de avaliação sobre os DE

\begin{tabular}{|c|c|c|c|}
\hline Ano & Organização & Objetivos dos estudos & Ref. \\
\hline 1995 & $\begin{array}{l}\text { Agência Ambiental } \\
\text { Federal Alemã }\end{array}$ & $\begin{array}{l}\text { Discussão sobre ocorrência e impacto dos DE e riscos potenciais que podem } \\
\text { causar aos humanos e outros animais }\end{array}$ & 32 \\
\hline 1995 & US EPA & Seminário para avaliar os riscos à saúde e efeitos ambientais dos DE & 33 \\
\hline 1995 & $\begin{array}{l}\text { Ministério do meio ambiente } \\
\text { e energia da Dinamarca }\end{array}$ & $\begin{array}{l}\text { Avaliação dos efeitos de substâncias estrogênicas no desenvolvimento e nas } \\
\text { funções do sistema reprodutivo masculino }\end{array}$ & 34 \\
\hline 1996 & US EPA & $\begin{array}{l}\text { Seminário para desenvolvimento de estratégia para avaliar o risco dos DE ao } \\
\text { meio ambiente }\end{array}$ & 35 \\
\hline 1996 & US EPA & $\begin{array}{l}\text { Desenvolvimento de programa de testes e análises ("screening") para avaliar } \\
\text { a ação dos DE }\end{array}$ & 36 \\
\hline 1997 & US EPA & Relatório sobre os DE presentes no meio ambiente & 16 \\
\hline 1998 & US EPA & Revisão e discussão das informações científicas disponíveis sobre os DE & 37 \\
\hline 1998 & OECD & Desenvolvimento de métodos de ensaio para os DE & 38 \\
\hline 1999 & CSTEE & $\begin{array}{l}\text { Revisão da literatura existente e opinião científica nas evidências dos } \mathrm{DE} \text {, em } \\
\text { particular, avaliação dos riscos ecológicos e diretrizes de ensaios toxicológicos }\end{array}$ & 39 \\
\hline 1999 & $\begin{array}{l}\text { Comissão das } \\
\text { Comunidades Européias }\end{array}$ & $\begin{array}{l}\text { Identificação do problema dos DE, suas causas, conseqüências e definição das } \\
\text { medidas adequadas para dar uma resposta ao problema }\end{array}$ & 17 \\
\hline 2001 & $\begin{array}{l}\text { Comissão das } \\
\text { Comunidades Européias }\end{array}$ & $\begin{array}{l}\text { Primeiro relatório sobre o progresso dos trabalhos da comunidade européia } \\
\text { sobre os DE }\end{array}$ & 40 \\
\hline 2002 & $\begin{array}{l}\text { Comissão das } \\
\text { Comunidades Européias }\end{array}$ & $\begin{array}{l}\text { Programa COMPREHEND: Avaliação das evidências dos DE no ambiente } \\
\text { aquático na Europa }\end{array}$ & 41 \\
\hline 2002 & OECD & Avaliação dos métodos de ensaios para as substâncias estrogênicas & 42 \\
\hline 2002 & WHO & Avaliação global do estado da arte da ciência dos DE & 43 \\
\hline 2003 & IEH & Relatório de avaliação do progresso internacional da pesquisa dos DE & 44 \\
\hline 2004 & $\begin{array}{l}\text { Comissão das } \\
\text { Comunidades Européias }\end{array}$ & Segundo relatório sobre o progresso dos trabalhos sobre os DE & 45 \\
\hline
\end{tabular}

Uma ação a curto prazo da Comissão Estratégica comunitária em matéria de desreguladores endócrinos estabelecida pela Comissão das Comunidades Européias foi o estabelecimento de uma lista prioritária de substâncias para uma futura avaliação do seu papel na desregulação endócrina. Assim, em 2000 foi proposta uma lista com 553 substâncias sintéticas e 9 hormônios naturais e sintéticos ${ }^{40}$. Dessas 553 substâncias, existem evidências de desregulação endócrina ou potencial de desregulação endócrina para 118 substâncias. Para as outras 435 substâncias, dados insuficientes foram apresentados nesse relatório. Baseado nisso, dois novos estudos foram iniciados; no primeiro foram avaliadas 9 substâncias sintéticas e 3 estrogênios das 118 substâncias apresentadas no relatório de 2000, que não tinham seus usos restringidos pela $\mathrm{UE}^{46}$. O segundo estudo abrange as 435 substâncias para as quais os dados foram insuficientes no relatório de 2000. Esta última lista foi dividida em três grupos de substâncias que dependem do volume de produção, da persistência no meio ambiente, das provas de desregulação endócrina encontradas em bibliografias científicas e nas considerações relativas à exposição (Anexo 1 de CEC, 2004 ${ }^{46}$ ). Fora da lista de 435 substâncias, outras 147 substâncias foram avaliadas; desse último grupo de substâncias, 129 eram restringidas pela UE por motivos distintos da desregulação endócrina.

As substâncias classificadas como DE, incluindo substâncias naturais e sintéticas, usadas ou produzidas para uma infinidade de finalidades podem ser agrupadas em duas classes: 1. substâncias sintéticas - utilizadas na agricultura e seus subprodutos, como pesticidas, herbicidas, fungicidas e moluscicidas; utilizadas nas indústrias e seus subprodutos, como dioxinas, PCB, alquilfenóis e seus subprodutos, HAP, ftalatos, bisfenol A, metais pesados, entre outros; compostos farmacêuticos, como os estrogênios sintéticos DES e $17 \alpha$-etinilestradiol e, 2. substâncias naturais - fitoestrogênios, tais como, genisteína e metaresinol e estrogênios naturais $17 \beta$ estradiol, estrona e estriol.
Resíduos de vários pesticidas vêm sendo encontrados em alimentos, água potável e corpos hídricos. Os pesticidas foram largamente utilizados no mundo por vários anos, sendo o maior grupo de substâncias classificadas como desreguladores endócrinos. Na classe dos pesticidas, estão inclusos inseticidas, herbicidas e fungicidas, que são utilizados na agricultura, na aqüicultura e no uso domiciliar.

Os hidrocarbonetos aromáticos policíclicos (HAP) são substâncias que apresentam potencial de bioacumulação e atividade estrogênica ${ }^{47}$ e podem ser encontrados na indústria petroquímica e na queima de gasolina e óleo diesel.

Alguns subprodutos de processos de combustão são suspeitos de serem desreguladores endócrinos, como os PCDD (policlorodibenzo-p-dioxinas) e PCDF (policlorodibenzofuranos), comumente chamados de dioxinas e furanos, respectivamente. Esses organoclorados podem ser produzidos durante a incineração de hidrocarbonetos clorados e do papel, na produção de PVC e de compostos aromáticos clorados, como o 2,4,5-triclorofenol. Pesquisas mostram que essas substâncias persistem e bioacumulam no meio ambiente ${ }^{48}$.

Outros organoclorados, como as bifenilas policloradas (PCB) que também apresentam atividade estrogênica. No passado, eram utilizados em várias aplicações, como fluidos de transferência de calor em transformadores e como fluidos dielétricos em capacitores. Contudo, ainda que não estejam mais sendo usados, estão presentes em algumas instalações antigas².

Desreguladores endócrinos também são encontrados na indústria química, como detergentes, resinas, alguns aditivos e monômeros utilizados na produção de plásticos. Os ftalatos são usados como aditivos (plastificantes) em alguns plásticos, principalmente na produção de PVC. Podem ser encontrados em brinquedos infantis, embalagens de produtos alimentícios e equipamentos médicos. Devido a sua persistência no meio ambiente, os ftalatos são comumente encontrados em águas superficiais e de subsolo ${ }^{49,50}$. 
Os surfactantes alquilfenóis e seus etoxilados (APEO), particularmente o nonilfenol (NP), apresentam uma variedade de aplicações, incluindo detergentes industriais e domésticos, lubrificantes, emulsificantes e estão presentes em formulações de pesticidas, de tintas e de produtos de uso pessoal (maquiagem, cremes de pele, produtos para cabelo e banho $)^{2}$. As possíveis rotas de entrada dessas substâncias no meio ambiente são durante sua produção, uso e disposição. Nas ETE, os alquilfenóis polietoxilatos (AP) são inicialmente biodegradados, derivando em metabólitos persistentes e altamente lipofílicos, incluindo alquilfenóis etoxilatos e, finalmente, nos alquilfenóis, tais como nonilfenol (NP) e octilfenol (OP) ${ }^{51}$. Estes metabólitos são freqüentemente detectados nos efluentes de ETE e águas superficiais ${ }^{52,53}$, sendo também relatados seus efeitos em organismos expostos a essas substâncias estrogênicas ${ }^{54}$.

O bisfenol A é extensamente usado na produção de plásticos, em particular os policarbonatos e resinas epóxi ${ }^{55,56}$. Pode ainda ser encontrado em adesivos, papéis para fax, tubulações, painéis de carros e produtos eletrônicos. Também estão presentes em revestimentos de latas de conservas e frascos de alimentos para bebês, podendo ser liberado destes causando problemas para a saúde humana. Alguns polímeros usados no tratamento dentário também contêm bisfenol A. A exposição humana a esse composto é considerável ${ }^{55,57}$ e sua atividade estrogênica tem sido muito relatada ${ }^{58-60}$.

Os retardadores de chama bromados (BFR), os chamados difenil-éteres polibromados (PBDE), são um grupo de substâncias químicas adicionadas em alguns produtos, como computadores, TV e tecidos domésticos para atrasar a combustão. Essas substâncias são persistentes, lipofílicas e bioacumulativas².

Os parabenos são ésteres de alquil de ácido para-hidrobenzóico, compostos utilizados como conservantes em cosméticos e em algumas pastas dentárias. Vários compostos deste grupo apresentam atividade estrogênica ${ }^{61}$.

Alguns agentes terapêuticos e farmacêuticos também estão na lista das substâncias classificadas como desreguladores endócrinos. São estrogênios sintéticos usados como contraceptivos orais, na reposição terapêutica na menopausa ou na prevenção do aborto, tais como, DES e o $17 \alpha$-etinilestradiol. A maior aplicação médica do $17 \alpha$-etinilestradiol tem sido no desenvolvimento de pílulas contraceptivas, que contêm de 30 a $50 \mu \mathrm{g}$ de $17 \alpha$-etinilestradiol por pílula ${ }^{62}$. O DES foi muito usado nos anos 70 na prevenção do aborto ${ }^{2}$.

Os compostos orgânicos contendo estanho são substâncias que também causam efeitos no sistema endócrino de animais. Esses compostos possuem uma infinidade de aplicações, sendo seu maior uso em tintas usadas no casco de embarcações para protegê-las da ação de organismos incrustantes (antiincrustantes), além de também serem utilizados como estabilizantes em plásticos e pesticidas ${ }^{63}$. Podem ser detectados em águas naturais e sedimentos marinhos, impondo grande risco aos organismos aquáticos. Estudos demonstraram o desenvolvimento de anomalias no sistema reprodutivo relacionado à exposição de animais aquáticos a esses compostos ${ }^{29,32}$.

Recentes estudos experimentais têm investigado a capacidade de baixas doses de metais pesados (cádmio, mercúrio, zinco, chumbo) causarem alterações nas funções do sistema endócrino. São relatadas alterações no sistema reprodutivo em populações de espécies de peixes, distúrbios na síntese de cortisol em peixes, indução da síntese de VTG $^{64,65}$

Uma variedade de hormônios naturais é encontrada em plantas e são chamados de fitoestrogênios. Uma grande quantidade dessas substâncias é absorvida através da dieta alimentar. Alimentos como grãos integrais, ervilhas, feijão, alguns vegetais e frutas contêm fitoestrogênios. A soja e os alimentos baseados em soja, como tofu, são alguns dos alimentos que possuem essas substâncias. Os fitoestrogênios mais estudados são da classe dos lignanos e das isoflavonas. Os fitoestrogênios são compostos naturais mais fracos que os estrogênios endógenos. Estudos indicam que essas substâncias podem se acoplar aos RE e podem funcionar como agonistas ou antagonistas no sistema endócrino ${ }^{2}$.

Pesquisadores têm chegado a conclusões dúbias quanto aos benefícios e/ou efeitos danosos dos fitoestrogênios. Segundo a Comissão das Comunidades Européias ${ }^{17}$, os fitoestrogênios apresentam alguns efeitos benéficos comprovados para a saúde humana, tais como, na prevenção das doenças cardiovasculares, da osteoporose e de alguns tipos de câncer. Acredita-se que o corpo humano consiga decompor facilmente e excretar rapidamente essas substâncias, significando que elas passam pouquíssimo tempo no organismo e não se acumulam gradualmente nos tecidos, como acontece com algumas substâncias sintéticas. Todavia, podem existir alguns riscos associados às alterações de estilo de vida e à mudança dos hábitos alimentares e de consumo, que levem a um maior consumo de alimentos que contenham estas substâncias.

Estrogênios naturais também fazem parte da classe dos desreguladores endócrinos. Pesquisas demonstram que os estrogênios estrona e $17 \beta$-estradiol são os maiores responsáveis pela atividade estrogênica nos efluentes de ETE $^{66}$. Estrogênios naturais também são encontrados em águas naturais, no solo e lodos biológicos em várias partes do mundo ${ }^{11,67,68}$. Esses estrogênios são naturalmente e diariamente excretados na urina humana e, assim, descartados no esgoto doméstico.

Algumas dessas substâncias tiveram seus usos proibidos ou não são mais produzidas, porém ainda podem ser encontradas no meio ambiente. A Tabela 2 apresenta algumas substâncias conhecidas ou suspeitas de serem desreguladores endócrinos. Uma lista mais completa com aproximadamente 560 substâncias pode ser encontrada no Anexo 1 do relatório COM (2001) $262^{40}$ da Comissão das Comunidades Européias.

\section{MEIOS DE EXPOSIÇÃO AOS DESREGULADORES ENDÓCRINOS}

Toneladas de substâncias sintéticas e naturais são lançadas anualmente no meio ambiente, das quais, um número considerável é de desreguladores endócrinos. Além de serem associados aos efeitos no sistema endócrino, alguns são também persistentes, lipofílicos, bioacumulativos e têm baixa pressão de vapor, o que facilita a dispersão e difusão no meio ambiente.

A exposição aos desreguladores endócrinos pode ocorrer sob diferentes formas, como através do contato direto no local de trabalho ou em casa, ou indireto através da ingestão de água, ar ou alimentos contaminados e ao contato com o solo. Uma das maiores exposições da população aos desreguladores endócrinos é através da ingestão de alimentos contaminados. No caso dos seres humanos estima-se que mais de $90 \%$ dessas substâncias ambientais são absorvidos por via digestiva, principalmente através de alimentos contaminados ${ }^{61}$.

Alguns desreguladores endócrinos são solúveis em gordura, assim, altos níveis podem estar presentes em carne, peixe, ovos e derivados do leite. Hartmann et al. ${ }^{69}$ relataram a ocorrência de hormônios sexuais (17 $\beta$-estradiol, estrona, testosterona e progesterona) em carnes (gado, porco, aves, peixe), leite e seus derivados, ovos e plantas (gramíneas e leguminosas). A contaminação de alimentos também pode vir do fato de que alguns hormônios são aplicados na criação de animais e consumidos na alimentação humana, contudo, em grande parte dos países essa prática está proibida $^{70}$.

A exposição também pode vir de pesticidas residuais que contaminam frutas, vegetais e em baixas concentrações a água potá- 
Tabela 2. Algumas substâncias químicas classificadas como DE

\begin{tabular}{l}
\hline \multicolumn{1}{c}{ Ftalatos } \\
\hline dimetil ftalato (DMP) \\
dietil ftalato (DEP) \\
di-iso-butil ftalato (DIBP) \\
di-n-butil ftalato (DBP) \\
butilbenzil ftalato (BBP) \\
dicicloexilo ftalato (DCHP) \\
di-(2-etil-exil) ftalato (DEHP) \\
di-n-octil ftalato (DOP) \\
di-isooctil ftalato (DIOP) \\
di-iso-nonil ftalato (DINP) \\
di-iso-decil ftalato (DIDP) \\
\hline
\end{tabular}

\begin{tabular}{|c|}
\hline Alquilfenóis \\
\hline $\begin{array}{l}\text { nonilfenol } \\
\text { nonilfenol etoxilado } \\
\text { octilfenol } \\
\text { octilfenoletoxilado }\end{array}$ \\
\hline Organoclorados \\
\hline $\begin{array}{l}\text { dibenzo-p-dioxina } \\
\text { TCDD }(2,3,7,8 \text {-tetraclorodibenzeno-p-dioxina) } \\
\text { TCDF }(2,3,7,8 \text {-tetraclorodibenzofurano })\end{array}$ \\
\hline
\end{tabular}

\begin{tabular}{ll}
\hline & Bisfenol \\
\hline bisfenol A & \\
\hline & Parabenos
\end{tabular}

benzilparabeno

isobutilparabeno

butilparabeno

n-propilparabeno

etilparabeno

metilparabeno

\begin{tabular}{ll}
\hline \multicolumn{1}{c}{ Hidrocarbonetos } & aromáticos policíclicos \\
\hline naftalina & benzo[a]antraceno \\
acenaftileno & criseno \\
acenafteno & benzo[b]fluoranteno \\
fluoreno & benzo[k]fluoranteno \\
fenantreno & benzo[a]pireno \\
antraceno & indeno[123-cd]pireno \\
fluoranteno & dibenzo[ah]antraceno \\
pireno & benzo[ghi]perileno \\
\hline
\end{tabular}

Metais Pesados

cádmio

mercúrio

chumbo

zinco

vel. Junto com alguns pesticidas também podem estar presentes o nonilfenol e seus etoxilados, que são usados na formulação de alguns pesticidas. Outras fontes de exposição direta dos alquilfenóis são através do uso de produtos pessoais, como maquiagem, cremes, produtos para cabelo e banho ${ }^{2}$.

O bisfenol A é usado em revestimento de algumas latas de alimentos, enquanto os ftalatos são encontrados em outras embalagens de alimentos e em brinquedos infantis ${ }^{71}$. Estudos demonstram que resíduos de bisfenol A podem ser encontrados em alguns alimentos

\begin{tabular}{ll}
\hline \multicolumn{2}{c}{ Pesticidas } \\
\hline Inseticidas: & $\frac{\text { Fungicidas: }}{\text { vinclozolina }}$ \\
DDT (2,2 bis-p-clorofenil- & carbendazime \\
$1,1,1$-tricloroetano) & penconazol \\
DDE $(2,2$ bis-p-clorofenil- & procloraz \\
1,1dicloroetileno & propiconazol \\
deltametrin & epoxiconazol \\
carbofurano & procimidona \\
Herbicidas: & tridemorfos \\
\hline atrazina linuron & \\
\hline
\end{tabular}

Pesticidas organoclorados:

lindane (1,2,3,4,5,6-hexacloroexano)

\section{Compostos orgânicos de estanho}

tributilestanho (TBT) e trifenilestanho (TPT)

Policlorados de bifenilas

2,4,4'-triclorobifenil

$2,2^{\prime}, 5,5^{\prime}$ 'tetraclorobifenil

2,2', 4,5,5' 'pentaclorobifenil

2,3',4,4',5-pentaclorobifenil

2,2',3,4,4',5'-hexaclorobifenil

$2,2^{\prime}, 4,4^{\prime}, 5,5^{\prime}$-hexaclorobifenil

2,2',3,4,4',5,5'-heptaclorobifenil

Retardantes de chama bromado

Polibromobifenila (PBB)

2,2',4,4'-tetrabromodifenil éter (BDE 47)

2,2',4,4',5-pentabromodifenil éter (BDE 99)

2,2',4,4',6-pentabromodifenil éter (BDE 100)

2,2',4,4',5,5'-hexabromodifenil éter (BDE 153)

2,2',4,4',5,6'-hexabromodifenil éter (BDE 154)

2,2',3,4,4',5',6-heptabromodifenil éter

octabromodifenil éter (BDE octa)

decabromodifenil éter (BDE 209)

hexabromociclododecano (HBCD)

tetrabromobisfenol A (TBBA)

\section{Fitoestrogênios}

Isoflavona: daidzeína e genisteína.

Lignanas: metaresinol e enterodiol

$\frac{\text { Agentes terapêuticos e farmacêuticos }}{\text { dietilestilbestrol }(\mathrm{DES})}$
$\frac{17 \alpha \text {-etinilestradiol }\left(\mathrm{EE}_{2}\right)}{\text { Estrogênios naturais }}$
$\frac{17 \beta \text {-estradiol }\left(\mathrm{E}_{2}\right)}{\text { estrona }\left(\mathrm{E}_{1}\right)}$

humanos devido a sua migração das embalagens ${ }^{55,72}$. Por ter uso doméstico e industrial, o bisfenol A também pode ser encontrado no esgoto doméstico, efluente e lodo biológico de ETE ${ }^{56}$. Ambos, bisfenol A e ftalatos, podem ser lançados no meio ambiente durante o processo de produção e pela lixiviação dos produtos finais.

A variedade de produtos de PVC com aditivos, os ftalatos, presente nas residências pode expor diariamente as pessoas a múltiplas fontes de contaminação. Estudos científicos sobre a exposição humana a esses compostos começam a serem apresentados em todo 
o mundo e alguns investigam a hipótese de que alguns plásticos, como o PVC, podem afetar a saúde se colocados na boca por crianças muito pequenas ${ }^{73}$. Entretanto, para alguns autores, os riscos associados com a exposição oral a alguns ftalatos presentes em produtos infantis não foram confirmados ${ }^{74}$. De qualquer forma, organizações de alguns países determinaram a remoção de ftalatos em produtos para crianças ${ }^{74}$.

Recentemente, ftalatos, HAP, PCD, alquilfenóis e seus metabólitos, pesticidas e retardadores de chama bromados foram encontrados no ar e na poeira de residências ${ }^{75}$, portanto uma outra via de contaminação pode ser a respiratória.

Os desreguladores endócrinos também podem ser encontrados nas cinzas dos produtos incinerados, no lodo biológico de estações de tratamento de efluentes e em chorumes de aterros sanitários. Uma quantidade considerável de produtos industrializados potencialmente danosos é disposta diretamente no solo ou em aterros sanitários. Conseqüentemente, alguns desreguladores endócrinos, tais como PCDD, PCDF, bisfenol A, nonilfenol, octilfenol e $17 \alpha$-etinilestradiol e alguns ftalatos e pesticidas foram encontrados no chorume de aterros sanitários ${ }^{76}$.

A água potável é outra significativa fonte de exposição a desreguladores endócrinos. As águas superficiais e de subsolo, principais fontes de água potável, podem ser contaminadas pela infiltração de substâncias químicas através do solo, na agricultura ou mesmo em áreas urbanas, ou no descarte de efluentes industrial e doméstico, sendo que muitas dessas substâncias não são removidas pelos processos convencionais de tratamento de água.

Estudos demonstraram que o esterco animal afeta a qualidade das águas superficiais e de subsolo. Peterson et al. ${ }^{70}$ relataram a presença de $17 \beta$-estradiol (6 a $66 \mathrm{ng} \mathrm{L}^{-1}$ ) em águas subterrâneas próximas a áreas com alta densidade de criação de animais. Os estrogênios são naturalmente excretados pelos animais, ou são administrados como promotores de crescimento ${ }^{70,77}$, sendo que esta prática não é mais usada em muitos países.

Os efeitos dos desreguladores endócrinos no meio ambiente não dependem somente das suas concentrações no ambiente, mas também de outros fatores, tais como, lipofilicidade, persistência, bioacumulação, tempo de exposição, mecanismos de biotransformação e de excreção etc. Algumas substâncias presentes no meio ambiente sofrem biotransformação, resultando em metabólitos ou subprodutos igualmente ou até mais danosos que os compostos originais.

A exposição a baixos níveis de desreguladores endócrinos, que bioacumulam com o tempo, pode levar aos seus altos níveis no corpo de animais. Por isso, em uma cadeia alimentar, os animais que se encontram no topo da cadeia apresentam concentrações mais altas dessas substâncias no corpo que os organismos do início da cadeia alimentar.

Uma fonte de exposição bastante crítica é a presença dessas substâncias químicas nos organismos das fêmeas, que podem ser transferidas aos embriões, fetos ou filhotes através de ovos, placenta ou leite materno e, assim, afetar o desenvolvimento. Os hormônios desempenham um papel muito importante no desenvolvimento embrionário e fetal; segundo Reys ${ }^{61}$, nos mamíferos alguns desreguladores endócrinos atravessam a barreira placentária afetando o desenvolvimento do feto e podem igualmente ultrapassar a barreira hemato-encefálica e exercer seus efeitos no sistema nervoso. Nos animais aquáticos, a exposição aos poluentes é inevitável, pois grande parte do ciclo reprodutivo ocorre fora do corpo das fêmeas, proporcionando um contato direto durante a fase gestacional.

\section{OCORRÊNCIA DE DESREGULADORES ENDÓCRINOS NO MEIO AMBIENTE}

O monitoramento da presença de DE no meio ambiente tem sido realizado em uma grande variedade de estudos em todo mundo. No ambiente aquático, essas substâncias são encontradas nas águas superficiais e de subsolo, sedimentos marinhos, solo, efluentes e lodo biológico das ETE e água potável. São continuamente introduzidos no meio ambiente em concentrações detectáveis e podem afetar a qualidade da água, a saúde dos ecossistemas e, potencialmente, impactar o suprimento de água potável.

Os efluentes de ETE são importantes fontes de lançamento de substâncias estrogênicas no ambiente aquático. Desbrow et al. ${ }^{20} \mathrm{e}$ Jobling et al. ${ }^{78}$ demonstraram que os estrogênios naturais $(17 \beta$ estradiol e estrona) e sintético (17 $\alpha$-etinilestradiol) são responsáveis pela maior parte da atividade estrogênica detectada em efluentes de ETE no Reino Unido. A atividade estrogênica também foi detectada em efluentes de ETE da Alemanha ${ }^{79,80}$, Suécia ${ }^{81}$ e Reino Unido ${ }^{82,83}$.

Os estrogênios estrona, $17 \beta$-estradiol e $17 \alpha$-etinilestradiol recebem uma atenção especial, pois são continua e diariamente excretados no esgoto e não são completamente removidos nas $\mathrm{ETE}^{11,12}$. Com isso, são lançados continuamente nos sistemas aquáticos e podem ser encontrados nas águas superficiais, muitas vezes usadas como suprimento de água potável. Como os processos convencionais de tratamento de água não removem totalmente esses micropoluentes ${ }^{78}$, um risco constante é imposto aos humanos e às espécies animais. Os estrogênios naturais são excretados na urina por mulheres, animais fêmeas e, em menor quantidade, por homens na forma de conjugados polares inativos, predominantemente como glucuronides e sulfatos. Porém, estudos demonstram que esses estrogênios são encontrados nas ETE na forma livre, sugerindo que ocorrem reações de transformação dessas substâncias durante o processo de tratamento na ETE ${ }^{11,84}$. Johnson et al. ${ }^{85}$ revisaram as quantidades diárias excretadas dos estrogênios naturais 17 $\beta$-estradiol, estrona, estriol e a quantidade de $17 \alpha$-etinilestradiol nas pílulas orais contraceptivas e estimaram as excreções diárias de estrogênios por humanos, Tabela 3 .

Tabela 3. Excreção diária $(\mu \mathrm{g})$ per capita de estrogênios por humanos

\begin{tabular}{lcccc}
\hline Categoria & estrona & $\begin{array}{c}17 \beta- \\
\text { estradiol }\end{array}$ & estriol & $\begin{array}{c}17 \alpha- \\
\text { etinil- } \\
\text { estradiol }\end{array}$ \\
\hline Homens & 3,9 & 1,6 & 1,5 & - \\
Mulheres menstruando & 8 & 3,5 & 4,8 & - \\
Mulheres na menopausa & 4 & 2,3 & 1 & - \\
Mulheres grávidas & 600 & 259 & 6.000 & - \\
Mulheres & - & - & - & 35 \\
\hline
\end{tabular}

No Brasil em 1997, Ternes et al. ${ }^{11}$ realizaram o monitoramento de estrogênios naturais e do contraceptivo sintético, 17 $\alpha$-etinilestradiol, na ETE da Penha/RJ. No esgoto doméstico, os estrogênios 17 $\beta$-estradiol e estrona foram detectados em concentrações de 0,021 e $0,04 \mu \mathrm{g} \mathrm{L}^{-1}$, respectivamente. As taxas de remoção de estrona observadas foram de $67 \%$ para o efluente tratado em filtro biológico e $83 \%$ para o efluente tratado pelo processo de lodos ativados. Para o $17 \beta$-estradiol, estas taxas foram de 92 e 99,9\% para o efluente tratado em filtro biológico e para o efluente tratado pelo processo de lodos ativados, respectivamente. Para o estrogênio contraceptivo $17 \alpha$-etinilestradiol, as taxas de remoção na ETE foram de 64 e $78 \%$ para o efluente do filtro biológico e para o efluente do tanque de lodos ativados. A Tabela 4 apresenta as remoções de estrogênios monitoradas por Ternes et al. ${ }^{11}$ na ETE da Penha/RJ.

Estudos mostram que outros desreguladores endócrinos, tais como, nonilfenóis etoxilados, nonilfenol, octilfenol, HAP, bisfenol A e pesticidas também foram identificados em efluentes de ETE e águas superficiais e subterrâneas ${ }^{86-89}$. O bisfenol A e o nonilfenol 
Tabela 4. Remoções de estrogênios monitoradas na ETE da Penha/RJ

\begin{tabular}{|c|c|c|c|}
\hline \multirow[t]{2}{*}{ Substância } & \multirow{2}{*}{$\begin{array}{c}\text { Carga de } \\
\text { estrogênios } \\
\text { no esgoto } \\
\text { doméstico }\left(\mathrm{g} \mathrm{dia}^{-1}\right)\end{array}$} & \multicolumn{2}{|c|}{ Remoção (\%) } \\
\hline & & $\begin{array}{c}\text { Efluente } \\
\text { tratado/filtro } \\
\text { biológico }\end{array}$ & $\begin{array}{c}\text { Efluente } \\
\text { tratado/processo } \\
\text { de lodos ativados }\end{array}$ \\
\hline Estrona & 5,0 & 67 & 83 \\
\hline $17 \beta$-estradiol & 2,5 & 92 & 99,9 \\
\hline $17 \alpha$-etinilestradiol & 0,6 & 64 & 78 \\
\hline
\end{tabular}

são fracamente estrogênicos e freqüentemente com potenciais três ou mais ordens de magnitude menores que os estrogênios estrona, $17 \beta$-estradiol e $17 \alpha$-etinilestradiol.

Körner et $a l .^{90}$ investigaram a remoção da atividade estrogênica do efluente doméstico em uma planta de tratamento na Alemanha, verificaram que $90 \%$ da atividade estrogênica foi removida e somente $2,8 \%$ da atividade estrogênica foi encontrada no lodo biológico, concluindo que a maior parte das substâncias responsáveis pela estrogenicidade do esgoto doméstico foi de fato biodegradada e não ficaram adsorvidas nas partículas sólidas ou no lodo biológico. Porém, as taxas de eliminação individuais das substâncias foram diferentes, algumas foram totalmente removidas enquanto que outras foram ainda detectadas no efluente da ETE, tais como, bisfenol A, octilfenol e nonilfenol. Outros estudos mostram uma variação da taxa de adsorção dessas substâncias no lodo biológi$\operatorname{co}^{84,91}$. A adsorção dessas substâncias no lodo biológico é um importante caminho para sua remoção, o que justifica a quantificação da sua adsorção no lodo biológico de ETE ${ }^{5,84,92}$.

Compostos orgânicos contendo estanho (TBT e TPT) também foram detectados em águas superficiais e sedimentos marinhos no litoral do Brasil. O TBT acumula-se nos sedimentos em concentrações em média três mil vezes maiores que as detectadas na água ${ }^{29}$.

A Tabela 5 apresenta uma compilação das concentrações médias ou faixas de concentração de alguns desreguladores endócrinos detectados no meio ambiente, em trabalhos conduzidos por diversos autores.

\section{EFEITOS CAUSADOS PELA EXPOSIÇÃO AOS DESREGULADORES ENDÓCRINOS}

Recentemente, muitos efeitos causados pelos desreguladores endócrinos têm sido relatados, incluindo anomalias no sistema reprodutivo de animais (peixes, répteis e pássaros); indução da síntese de vitelogenina (VTG) no plasma de peixes e efeitos na saúde de humanos, tais como, redução na produção de esperma e aumento da incidência de alguns tipos de câncer.

Os riscos em potencial dos desreguladores endócrinos têm sido tema de vários debates internacionais e pesquisas científicas ${ }^{16,18,28,32,39,102}$. O ponto principal desta questão é se há evidências significativas de que essas substâncias possam causar efeitos danosos em humanos e outros animais e se há níveis suficientes de desreguladores endócrinos no meio ambiente para exercerem esses efeitos.

\section{Efeitos relatados em animais silvestres e de laboratório}

Vários estudos relacionam a poluição ambiental das águas naturais com anomalias no sistema reprodutivo e no desenvolvimento de espécies de animais. A exposição aos desreguladores endócrinos pode ser responsável por alterações fisiológicas e histológicas em animais silvestres e de laboratório, incluindo alterações nos níveis de VTG no plasma sangüíneo, feminização de peixes machos, indução ao hermafroditismo, inibição no desenvolvimento das gônadas e declínio na reprodução. Essas e outras anomalias relatadas em várias espécies de animais são apresentadas nas Tabelas 6 e 7 .

Vários estudos mostram que organismos aquáticos respondem com indução da síntese de VTG à exposição a determinadas concentrações de estrogênios ${ }^{116,123,129}$.

No estudo de Routledge et al..$^{82}$, duas espécies de peixes, Oncorhynchus mykiss e Rutilus rutilus, foram expostas por 21 dias a concentrações de $17 \beta$-estradiol e estrona ambientalmente relevantes (1, 10, $\left.100 \mathrm{ng} \mathrm{L}^{-1}\right)$. De acordo com esses e outros pesquisadores, os resultados confirmaram que os estrogênios identificados em efluentes domésticos estão presentes em quantidades suficientes para induzir

Tabela 5. Sumário das concentrações médias ou faixas de concentrações de desreguladores endócrinos detectados no meio ambiente

\begin{tabular}{|c|c|c|c|c|}
\hline Substância & Classe da substância & Concentrações no ambiente & Condições & Ref. \\
\hline Antraceno & HAP & $0,07 \mu \mathrm{g} \mathrm{L}-1$ & Água natural/EUA & 88 \\
\hline \multirow[t]{14}{*}{ Bisfenol A } & Bisfenol & $0,005-0,05 \mu \mathrm{g} \mathrm{L}^{-1}$ & Efluente de ETE/Alemanha & 53 \\
\hline & & $0,0005-0,014 \mu \mathrm{g} \mathrm{L}^{-1}$ & Água superficial/Alemanha & \\
\hline & & $0,0005-0,002 \mu \mathrm{g} \mathrm{L}^{-1}$ & Água potável/Alemanha & \\
\hline & & $0,14 \mu \mathrm{g} \mathrm{L}^{-1}$ & Água natural/EUA & 88 \\
\hline & & $0,0005-0,41 \mu \mathrm{g} \mathrm{L}^{-1}$ & Água superficial/Alemanha & 57 \\
\hline & & $0,018-0,702 \mu \mathrm{g} \mathrm{L}^{-1}$ & Efluente de ETE/Alemanha & \\
\hline & & $0,01-0,19 \mu \mathrm{g} \mathrm{kg}^{-1}$ & Sedimento marinho/Alemanha & \\
\hline & & $0,004-1,363 \mathrm{mg} \mathrm{kg}^{-1}$ peso seco & Lodo biológico de ETE/Alemanha & \\
\hline & & $0,33-0,34 \mu \mathrm{g} \mathrm{L}^{-1}$ & Afluente de ETE/Itália & 93 \\
\hline & & $0,013-0,036 \mu \mathrm{g} \mathrm{L}^{-1}$ & Efluente de ETE/Itália & \\
\hline & & $0,015-0,029 \mu \mathrm{g} \mathrm{L}^{-1}$ & Água superficial/Itália & \\
\hline & & $0,3-5,6 \mu \mathrm{g} \mathrm{L}^{-1}$ & Água superficial/Portugal & 94 \\
\hline & & $7-58 \mu \mathrm{g} \mathrm{g}^{-1}$ & Recipiente de PC para alimentos & 55 \\
\hline & & $0,0001-0,0047 \mu \mathrm{g} \mathrm{L}^{-1}$ & Água armazenada em recipientes de PC & \\
\hline Dietilftalato & Ftalato & $0,2 \mu \mathrm{g} \mathrm{L}^{-1}$ & Água natural/EUA & 88 \\
\hline Di-(2-etil-exil) & Ftalato & $0,33-97,8 \mu \mathrm{g} \mathrm{L}^{-1}$ & Água superficial/Alemanha & 57 \\
\hline \multirow[t]{3}{*}{ ftalato (DEHP) } & & $1,74-182 \mu \mathrm{g} \mathrm{L}^{-1}$ & Efluente de ETE/Alemanha & \\
\hline & & $0,21-8,44 \mu \mathrm{g} \mathrm{L}^{-1}$ & Sedimento marinho/Alemanha & \\
\hline & & $27,9-154 \mathrm{mg} \mathrm{kg}^{-1}$ peso seco & Lodo biológico de ETE/Alemanha & \\
\hline
\end{tabular}


Tabela 5. Continuação

\begin{tabular}{|c|c|c|c|c|}
\hline Substância & Classe da substância & Concentrações no ambiente & Condições & Ref. \\
\hline \multirow{4}{*}{$\begin{array}{l}\text { Di-n-butil ftalato } \\
\text { (DBP) }\end{array}$} & \multirow[t]{4}{*}{ Ftalato } & $0,12-8,80 \mu \mathrm{g} \mathrm{L}^{-1}$ & Água superficial/Alemanha & \multirow[t]{4}{*}{57} \\
\hline & & $0,2-10,4 \mu \mathrm{g} \mathrm{L}^{-1}$ & Efluente de ETE/Alemanha & \\
\hline & & $0,06-2,08 \mu \mathrm{g} \mathrm{L}^{-1}$ & Sedimento marinho/Alemanha & \\
\hline & & $0,06-2,08 \mathrm{mg} \mathrm{kg}^{-1}$ & Lodo biológico de ETE/Alemanha & \\
\hline \multirow[t]{22}{*}{$17 \alpha$-Etinilestradiol } & \multirow{22}{*}{$\begin{array}{l}\text { Estrogênio } \\
\text { sintético }\end{array}$} & $0,005 \mu \mathrm{g} \mathrm{L}^{-1}$ & Esgoto doméstico/Brasil & \multirow[t]{3}{*}{11} \\
\hline & & $0,001 \mu \mathrm{g} \mathrm{L}^{-1}$ & Efluente de ETE/Alemanha & \\
\hline & & $0,009 \mu \mathrm{g} \mathrm{L}^{-1}$ & Efluente de ETE/Canadá & \\
\hline & & $0,073 \mu \mathrm{g} \mathrm{L}^{-1}$ & Água natural/EUA & 88 \\
\hline & & $<0,2-7,6 \mathrm{ng} \mathrm{L}^{-1}$ & Efluente de ETE/Países Baixos & \multirow[t]{2}{*}{67} \\
\hline & & $<0,1-4,3 \mathrm{ng} \mathrm{L}^{-1}$ & Água superficial/Países Baixos & \\
\hline & & $<0,5-10 \mathrm{ng} \mathrm{L}^{-1}$ & Esgoto doméstico/Itália e Holanda & \multirow[t]{2}{*}{85} \\
\hline & & $<0,2-2,2 \mathrm{ng} \mathrm{L}^{-1}$ & Efluente de ETE/Itália e Holanda & \\
\hline & & $0,2-7,0 \mathrm{ng} \mathrm{L}^{-1}$ & Efluente de ETE/Inglaterra & 20 \\
\hline & & $0,005-0,007 \mu \mathrm{g} \mathrm{L}^{-1}$ & Afluente de ETE/França & \multirow[t]{3}{*}{95} \\
\hline & & $0,003-0,0045 \mu \mathrm{g} \mathrm{L}^{-1}$ & Efluente de ETE/França & \\
\hline & & $0,001-0,003 \mu \mathrm{g} \mathrm{L}^{-1}$ & Água superficial/França & \\
\hline & & $0,3-1,7 \mathrm{ng} \mathrm{L}^{-1}$ & Efluente de ETE/Itália & 96 \\
\hline & & $4,5 \mathrm{ng} \mathrm{L}^{-1}$ & Esgoto doméstico/Suécia & \multirow[t]{2}{*}{97} \\
\hline & & $2 \mathrm{ng} \mathrm{L}^{-1}$ & Efluente de ETE/Suécia & \\
\hline & & $2-17 \mathrm{ng} \mathrm{L}^{-1}$ & Lodo ativado de ETE/Alemanha & \multirow[t]{2}{*}{98} \\
\hline & & $0,9 \mathrm{ng} \mathrm{g}^{-1}$ & Sedimento marinho/Alemanha & \\
\hline & & $0,25-0,52 \mathrm{ng} \mathrm{L}^{-1}$ & Água superficial/EUA & \multirow[t]{2}{*}{99} \\
\hline & & $0,24-0,76 \mathrm{ng} \mathrm{L}^{-1}$ & Efluente de ETE/EUA & \\
\hline & & $0,1-8,9 \mathrm{ng} \mathrm{L}^{-1}$ & Efluente de ETE/Alemanha & \multirow[t]{3}{*}{53} \\
\hline & & $0,1-5,1 \mathrm{ng} \mathrm{L}^{-1}$ & Água biológica/Alemanha & \\
\hline & & $0,00015-0,0005 \mu \mathrm{g} \mathrm{L}^{-1}$ & Âgua potável/Alemanha & \\
\hline \multirow[t]{27}{*}{$17 \beta$-Estradiol } & \multirow{27}{*}{$\begin{array}{l}\text { Estrogênio } \\
\text { natural }\end{array}$} & $15 \mathrm{ng} \mathrm{L}^{-1}$ & Esgoto doméstico/Alemanha & 11 \\
\hline & & $6 \mathrm{ng} \mathrm{L}^{-1}$ & Efluente de ETE/Canadá & \\
\hline & & $21 \mathrm{ng} \mathrm{L}^{-1}$ & Esgoto doméstico/Brasil & \\
\hline & & $9-6 \mathrm{ng} \mathrm{L}^{-1}$ & Água natural/EUA & 88 \\
\hline & & $2-12 \mu \mathrm{g} / \mathrm{mulher} / \mathrm{dia}$ & Naturalmente excretado na urina & 67 \\
\hline & & $<0,6-12 \mathrm{ng} \mathrm{L}^{-1}$ & Efluente de ETE/Países Baixos & \\
\hline & & $<0,3-5,5 \mathrm{ng} \mathrm{L}^{-1}$ & Água superficial/Países Baixos & \\
\hline & & $<0,5-20 \mathrm{ng} \mathrm{L}^{-1}$ & Esgoto doméstico/Itália e Holanda & 85 \\
\hline & & $<0,5-7 \mathrm{ng} \mathrm{L}^{-1}$ & Efluente de ETE/Itália e Holanda & \\
\hline & & $11-17 \mathrm{ng} \mathrm{L}^{-1}$ & Afluente de ETE/França & 95 \\
\hline & & $5-9 \mathrm{ng} \mathrm{L}^{-1}$ & Efluente de ETE/França & \\
\hline & & $1-3 \mathrm{ng} \mathrm{L}^{-1}$ & Água superficial/França & \\
\hline & & $2,7-48 \mathrm{ng} \mathrm{L}^{-1}$ & Efluente de ETE/Inglaterra & 20 \\
\hline & & $0,5-7,0 \mathrm{ng} \mathrm{L}^{-1}$ & Água superficial/Inglaterra & 100 \\
\hline & & $1,6-7,4 \mathrm{ng} \mathrm{L}^{-1}$ & Efluente de ETE/Inglaterra & \\
\hline & & $1,1 \mathrm{ng} \mathrm{L}^{-1}$ & Esgoto doméstico/Suécia & 97 \\
\hline & & $0,5 \mathrm{ng} \mathrm{L}^{-1}$ & Efluente de ETE/Suécia & \\
\hline & & $5-49 \mathrm{ng} \mathrm{L}^{-1}$ & Lodo biológico de ETE/Alemanha & 98 \\
\hline & & $1,5 \mathrm{ng} \mathrm{g}^{-1}$ & Sedimento marinho/Alemanha & \\
\hline & & $0,27-2,67 \mathrm{ng} \mathrm{L}^{-1}$ & Água superficial/EUA & 99 \\
\hline & & $0,48-3,66 \mathrm{ng} \mathrm{L}^{-1}$ & Efluente de ETE/EUA & \\
\hline & & $10-31 \mathrm{ng} \mathrm{L}^{-1}$ & Afluente de ETE/Itália & 93 \\
\hline & & $3-8 \mathrm{ng} \mathrm{L}^{-1}$ & Efluente de ETE/Itália & \\
\hline & & $0,002-0,006 \mu \mathrm{g} \mathrm{L}^{-1}$ & Água superficial/Itália & \\
\hline & & $0,15-5,2 \mathrm{ng} \mathrm{L}^{-1}$ & Efluente de ETE/Alemanha & 53 \\
\hline & & $0,15-3,6 \mathrm{ng} \mathrm{L}^{-1}$ & Água superficial/Alemanha & \\
\hline & & $0,0002-0,002 \mu \mathrm{g} \mathrm{L}^{-1}$ & Água potável/Alemanha & \\
\hline Estrona & Estrogênio & 0,02 a $0,05 \mu \mathrm{g} \mathrm{L}^{-1}$ & Água superficial/Brasil & 101 \\
\hline & natural & $0,04 \mu \mathrm{g} \mathrm{L}^{-1}$ & Esgoto doméstico/Brasil & 11 \\
\hline & & $0,027 \mu \mathrm{g} \mathrm{L}^{-1}$ & Esgoto doméstico/Alemanha & \\
\hline & & $0,003 \mu \mathrm{g} \mathrm{L}^{-1}$ & Efluente de ETE no Canadá & \\
\hline & & $0,009 \mu \mathrm{g} \mathrm{L}^{-1}$ & Efluente de ETE/Alemanha & \\
\hline & & $0,7-1,6 \mathrm{ng} \mathrm{L}^{-1}$ & Água superficial/Alemanha & \\
\hline & & $0,001-0,018 \mu \mathrm{g} \mathrm{L}^{-1}$ & Afluente de ETE/França & 95 \\
\hline & & $0,004-0,007 \mu \mathrm{g} \mathrm{L}^{-1}$ & Efluente de ETE/França & \\
\hline & & $0,001-0,003 \mu \mathrm{g} \mathrm{L}^{-1}$ & Água superficial/França & \\
\hline & & $0,027 \mu \mathrm{g} \mathrm{L}^{-1}$ & Água natural/EUA & 88 \\
\hline
\end{tabular}


Tabela 5. Continuação

\begin{tabular}{|c|c|c|c|c|}
\hline Substância & Classe da substância & Concentrações no ambiente & Condições & Ref. \\
\hline \multirow[t]{19}{*}{ Estrona } & Estrogênio & $<0,4-47 \mathrm{ng} \mathrm{L}^{-1}$ & Efluente de ETE/Países Baixos & 67 \\
\hline & natural & $<0,1-3,4 \mathrm{ng} \mathrm{L}^{-1}$ & Água superficial/Países Baixos & \\
\hline & & $<0,5-75 \mathrm{ng} \mathrm{L}^{-1}$ & Esgoto doméstico/Itália/Holanda & 85 \\
\hline & & $<0,5-54 \mathrm{ng} \mathrm{L}^{-1}$ & Efluente de ETE/Itália/Holanda & \\
\hline & & $1,4-76 \mathrm{ng} \mathrm{L}^{-1}$ & Efluente de ETE/Inglaterra & 20 \\
\hline & & $20-132 \mathrm{ng} \mathrm{L}^{-1}$ & Esgoto doméstico/Itália & 96 \\
\hline & & $2,5-82,1 \mathrm{ng} \mathrm{L}^{-1}$ & Efluente de ETE/Itália & \\
\hline & & $6,4-29 \mathrm{ng} \mathrm{L}^{-1}$ & Efluente de ETE/Inglaterra & 100 \\
\hline & & $0,2-17 \mathrm{ng} \mathrm{L}^{-1}$ & Água natural/Inglaterra & \\
\hline & & $5,8 \mathrm{ng} \mathrm{L}^{-1}$ & Esgoto doméstico/Suécia & 97 \\
\hline & & $0,5 \mathrm{ng} \mathrm{L}^{-1}$ & Efluente de ETE/Suécia & \\
\hline & & $16-37 \mathrm{ng} \mathrm{g}^{-1}$ & Lodo biológico de ETE/Alemanha & 98 \\
\hline & & $2 \mathrm{ng} \mathrm{g}^{-1}$ & Sedimento marinho/Alemanha & \\
\hline & & $0,015-0,060 \mu \mathrm{g} \mathrm{L}^{-1}$ & Afluente de ETE/Itália & 93 \\
\hline & & $0,005-0,030 \mu \mathrm{g} \mathrm{L}^{-1}$ & Efluente de ETE/Itália & \\
\hline & & $0,005-0,012 \mu \mathrm{g} \mathrm{L}^{-1}$ & Água superficial/Itália & \\
\hline & & $0,35-18 \mathrm{ng} \mathrm{L}^{-1}$ & Efluente de ETE/Alemanha & 53 \\
\hline & & $0,1-4,1 \mathrm{ng} \mathrm{L}^{-1}$ & Água superficial/Alemanha & \\
\hline & & $0,2-0,6 \mathrm{ng} \mathrm{L}^{-1}$ & Água potável/Alemanha & \\
\hline \multirow[t]{13}{*}{ Estriol } & Estrogênio & $0,019 \mu \mathrm{g} \mathrm{L}^{-1}$ & Água natural/EUA & 88 \\
\hline & natural & $2-120 \mathrm{ng} \mathrm{L}^{-1}$ & Efluente de ETE/Países Baixos & 67 \\
\hline & & $<0,5-28 \mathrm{ng} \mathrm{L}^{-1}$ & Água superficial/Países Baixos & \\
\hline & & $24-188 \mathrm{ng} \mathrm{L}^{-1}$ & Esgoto doméstico/Itália & 96 \\
\hline & & $0,43-18 \mathrm{ng} \mathrm{L}^{-1}$ & Efluente de ETE/Itália & \\
\hline & & $2-4 \mathrm{ng} \mathrm{L}^{-1}$ & Água superficial/Inglaterra & 100 \\
\hline & & $1,2-3,1 \mathrm{ng} \mathrm{L}^{-1}$ & Água natural/Inglaterra & \\
\hline & & $0,023-0,048 \mu \mathrm{g} \mathrm{L}^{-1}$ & Afluente de ETE/Itália & 93 \\
\hline & & $0,001 \mu \mathrm{g} \mathrm{L}^{-1}$ & Efluente de ETE/Itália & \\
\hline & & $0,002-0,005 \mu \mathrm{g} \mathrm{L}^{-1}$ & Água superficial/Itália & \\
\hline & & $0,01-0,015 \mu \mathrm{g} \mathrm{L}^{-1}$ & Afluente de ETE/França & 95 \\
\hline & & $0,005-0,007 \mu \mathrm{g} \mathrm{L}^{-1}$ & Efluente de ETE/França & \\
\hline & & $0,001-0,003 \mu \mathrm{g} \mathrm{L}^{-1}$ & Água superficial/França & \\
\hline \multirow[t]{3}{*}{ Genisteína } & Fitoestrogênio & $0,2-0,4 \mu \mathrm{g} \mathrm{L}^{-1}$ & Afluente de ETE/Itália & 93 \\
\hline & & $0,015-0,083 \mu \mathrm{g} \mathrm{L}^{-1}$ & Efluente de ETE/Itália & \\
\hline & & $0,004-0,007 \mu \mathrm{g} \mathrm{L}^{-1}$ & Água superficial/Itália & \\
\hline Nonilfenol & Alquilfenol & $3,2-17,8 \mu \mathrm{g} \mathrm{L}^{-1}$ & Água superficial/EUA & 99 \\
\hline \multirow[t]{4}{*}{ polietoxilado (NPE) } & polietoxilado & $4,9-332,0 \mu \mathrm{g} \mathrm{L}^{-1}$ & Efluente de ETE/EUA & \\
\hline & & $24-938 \mu \mathrm{g} \mathrm{L}^{-1}$ & Afluente de ETE/Espanha & 52 \\
\hline & & $10 \mu \mathrm{g} \mathrm{L}^{-1}$ & Efluente de ETE/Espanha & \\
\hline & & $20-100 \mu \mathrm{g} \mathrm{L}^{-1}$ & Águas superficiais/Espanha & \\
\hline \multirow[t]{13}{*}{ Nonilfenol (NP) } & Produto de & $0,16-1,19 \mu \mathrm{g} \mathrm{L}^{-1}$ & Água superficial/EUA & 99 \\
\hline & degradação do & $0,17-37,0 \mu \mathrm{g} \mathrm{L}^{-1}$ & Efluente de ETE/EUA & \\
\hline & nonilfenol etoxilado & $0,8 \mu \mathrm{g} \mathrm{L}^{-1}$ & Água natural/EUA & 88 \\
\hline & (Alquilfenol etoxilado) & $0,258-0,77 \mu \mathrm{g} \mathrm{L}^{-1}$ & Efluente de ETE/Alemanha & 53 \\
\hline & & $0,007-0,134 \mu \mathrm{g} \mathrm{L}^{-1}$ & Água superficial/Alemanha & \\
\hline & & $0,003-0,016 \mu \mathrm{g} \mathrm{L}^{-1}$ & Água potável/Alemanha & \\
\hline & & $4,2-8,8 \mu \mathrm{g} \mathrm{L}^{-1}$ & Afluente de ETE/Itália & 93 \\
\hline & & $1,12-2,2 \mu \mathrm{g} \mathrm{L}^{-1}$ & Efluente de ETE/Itália & \\
\hline & & $1,3-1,5 \mu \mathrm{g} \mathrm{L}^{-1}$ & Água superficial/Itália & \\
\hline & & $0,2-4,0 \mu \mathrm{g} \mathrm{L}^{-1}$ & Água superficial/Portugal & 94 \\
\hline & & $40-343 \mu \mathrm{g} \mathrm{L}^{-1}$ & Afluente de ETE/Espanha & 52 \\
\hline & & $6-289 \mu \mathrm{g} \mathrm{L}^{-1}$ & Efluente de ETE/Espanha & \\
\hline & & $18-644 \mu \mathrm{g} \mathrm{L}^{-1}$ & Águas superficiais/Espanha & \\
\hline \multirow[t]{6}{*}{ Octilfenol (OP) } & Produto de & $0,005-0,08 \mu \mathrm{g} \mathrm{L}^{-1}$ & Água superficial/EUA & 99 \\
\hline & degradação do & $0,016-0,7 \mu \mathrm{g} \mathrm{L}^{-1}$ & Efluente de ETE/EUA & 88 \\
\hline & octilfenol etoxilado & $0,2 \mu \mathrm{g} \mathrm{L}^{-1}$ & Água natural/EUA & \\
\hline & (Alquilfenol etoxilato) & $0,002-0,073 \mu \mathrm{g} \mathrm{L}^{-1}$ & Efluente de ETE/Alemanha & 53 \\
\hline & & $0,0008-0,054 \mu \mathrm{g} \mathrm{L}^{-1}$ & Água superficial/Alemanha & \\
\hline & & $0,0002-0,005 \mu \mathrm{g} \mathrm{L}^{-1}$ & Água potável/Alemanha & \\
\hline Fenantreno & HAP & $0,04 \mu \mathrm{g} \mathrm{L}^{-1}$ & Água natural/EUA & 88 \\
\hline
\end{tabular}


Tabela 6. Efeitos e anomalias atribuídos aos DE

\begin{tabular}{|c|c|c|c|}
\hline Espécie & Contaminante & Efeitos & Ref. \\
\hline \multirow[t]{24}{*}{ Peixe } & Efluente de ETE & Feminização de peixes & 103 \\
\hline & & Declínio na reprodução & 104 \\
\hline & & Indução da síntese de VTG & $52,66,97,103,105-107$ \\
\hline & $17 \beta$-estradiol & Feminização de peixes & $83,90,108$ \\
\hline & & Alteração nas gônadas & 109 \\
\hline & & Hermafroditismo & 89,110 \\
\hline & & Incidência de testículo-óvulos nas gônadas & 111 \\
\hline & & Declínio na reprodução & 89,112 \\
\hline & & Inibição do crescimento testicular & 107 \\
\hline & & Mortalidade elevada dos descendentes & 108 \\
\hline & & Indução da síntese de VTG & $82,109,113,114$ \\
\hline & Estrona & Indução da síntese de VTG & 82,107 \\
\hline & & Inibição do crescimento testicular & 107 \\
\hline & $17 \alpha$-etinilestradiol & Indução da síntese de VTG & $114-116$ \\
\hline & & Mortalidade da espécie & 115 \\
\hline & & Declínio na reprodução & 104 \\
\hline & Bisfenol A e DEHP (ftalato) & Declínio na reprodução & 112 \\
\hline & Nonilfenol, octilfenol e butilfenol & Declínio na reprodução & \\
\hline & & Indução da síntese de VTG & 51,54 \\
\hline & & $\begin{array}{l}\text { Mortalidade elevada dos descendentes } \\
\text { e feminização de peixes machos }\end{array}$ & 108 \\
\hline & DES & Indução da síntese de VTG no sangue & 116 \\
\hline & 4-tert-pentilfenol & Feminização de peixes machos & 117 \\
\hline & Cádmio, mercúrio e zinco & Distúrbios na síntese de cortisol & 65 \\
\hline & HAP, mercúrio, chumbo e cádmio & Indução da síntese de VTG & 64 \\
\hline
\end{tabular}

Tabela 7. Efeitos e anomalias atribuídos aos DE

\begin{tabular}{|c|c|c|c|}
\hline Espécie & Contaminante & Efeitos & Ref. \\
\hline \multirow[t]{3}{*}{ Mamífero } & Bisfenol A & Anomalias no sistema reprodutivo de ratos & 118 \\
\hline & PCB & Alta mortalidade de golfinhos & 119 \\
\hline & DDT & Anomalias no sistema reprodutivo de ratos & 120 \\
\hline Réptil & DDE e DDT & $\begin{array}{l}\text { Concentrações anormais de hormônios sexuais } \\
\text { no plasma (baixa concentração de testosterona) } \\
\text { e anomalias morfológicas nas gônadas } \\
\text { (redução no tamanho do pênis) em jacarés }\end{array}$ & $3,121,122$ \\
\hline Mexilhão & Efluente de ETE & $\begin{array}{l}\text { Indução da síntese de VTG e anomalias } \\
\text { no crescimento da concha dos mexilhões }\end{array}$ & 123 \\
\hline Molusco & TBT e TPT & $\begin{array}{c}\text { Desenvolvimento de órgãos sexuais masculinos } \\
\text { em fêmeas - imposex e esterilização }\end{array}$ & 29 \\
\hline Tartaruga & $17 \beta$-estradiol & Indução à síntese de VTG no sangue e alterações na produção de ovos & 124 \\
\hline \multirow[t]{3}{*}{ Pássaro } & Pesticidas & Decréscimo na fertilidade & 125 \\
\hline & DDT & Feminização de gaivotas machos & 126 \\
\hline & & Anomalias no sistema reprodutivo & 120 \\
\hline \multirow[t]{2}{*}{ Anfíbio } & Herbicida (atrazina) & Anomalias no sistema reprodutivo e declínio da população & 127 \\
\hline & Efluente de ETE & Indução à síntese de VTG no sangue e hermafroditismo & 128 \\
\hline
\end{tabular}

a síntese de VTG em espécies de peixes ${ }^{20}$. Efluentes de ETE vêm sendo apontados como a maior causa de efeitos estrogênicos em peixes. Rodgres-Gray et al. ${ }^{105}$ observaram um aumento nos níveis de VTG no plasma de peixes da espécie Rutilus rutilus quando expostos ao efluente de ETE do Reino Unido. Neste efluente foi detectada a presença dos estrogênios $17 \beta$-estradiol, estrona e $17 \alpha$-etinilestradiol nas concentrações de 4, 50 e 1,7-3,4 ng L L $^{-1}$, respectivamente.

A indução da síntese de VTG não ocorre só em espécies de peixes, mas também em outras espécies de animais. Concentrações ambientalmente relevantes de $17 \beta$-estradiol são suficientes para induzir a síntese de VTG em tartarugas ${ }^{123}$ e em mexilhões (Elliptio complanata) ${ }^{123}$.
Espécies de jacarés jovens que viveram em lagos da Flórida poluídos apresentaram anomalias no sistema reprodutivo, tais como, concentrações anormais de hormônios sexuais no plasma (baixa concentração de testosterona) e anomalias morfológicas nas gônadas

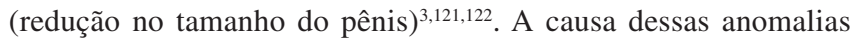
pode estar relacionada com a presença de substâncias estrogênicas e anti-andrógenas. O principal poluente encontrado nesses jacarés foi o DDE, o mais persistente metabólito do DDT ${ }^{121}$.

Alguns moluscos (caramujos e lesmas) que vivem no litoral brasileiro desenvolveram anomalias no sistema reprodutivo resultante da exposição ao TBT. Esses compostos orgânicos contendo 
estanho, oriundos da tinta dos cascos das embarcações, estão provocando o surgimento de órgãos masculinos em fêmeas, fenômeno conhecido como imposex - imposição sexual - que é irreversível e provoca a esterilização das espécies, podendo causar declínio considerável nas populações de espécies mais sensíveis. Essas substâncias interferem na síntese da testosterona (hormônio masculino), causando um aumento na sua produção nas fêmeas. Essa alteração hormonal faz surgir estruturas sexuais masculinas não funcionais, mantendo-se, porém, a anatomia interna do organismo ${ }^{29}$.

Efeitos adversos no sistema reprodutivo de pássaros também podem estar relacionados com a exposição aos desreguladores endócrinos, tais como, pesticidas (DDT, dicofol) e PCB. Foram observadas anomalias em embriões machos e fêmeas, como por ex., a feminização dos machos ${ }^{125}$.

Várias espécies de peixes são usadas como modelo para detectar os efeitos de desreguladores endócrinos no desenvolvimento de anomalias no sistema reprodutivo. Peixes da espécie Oryzias latipes são excelentes organismos para estudos de reprodução, pois apresentam a diferenciação sexual antes da eclosão dos ovos, podem reproduzir todos os dias sob condições apropriadas e levam poucos meses para atingir a maturidade ${ }^{111,112}$.

O estudo de Legler et al. ${ }^{9}$ mostrou que as substâncias com atividade estrogênica não só são importantes na fase aquosa, mas também podem acumular-se em sedimentos marinhos e expor os organismos em ambientes aquáticos a substâncias com atividade estrogênica. No estudo de Janssen et al. ${ }^{130}$, peixes da espécie Platichthys flesus foram expostos a sedimentos contendo DE, resultando em um prematuro aumento dos níveis de VTG no plasma dos peixes fêmeas.

\section{Efeitos relatados em humanos}

Uma variedade de substâncias químicas é suspeita de causar efeitos adversos na saúde humana, resultando em alterações no sistema endócrino, incluindo efeitos no sistema reprodutivo feminino (diferenciação sexual, função dos ovários, aumento no risco de câncer de mama e de vagina, ovários policísticos e endometriose) e no sistema reprodutivo masculino (redução na produção de esperma, aumento do risco de câncer testicular e de próstata, infertilidade e alterações nos níveis hormonais da tireóide). Esses e outros efeitos foram revisados em alguns estudos ${ }^{16,131-133}$.

No que diz respeito aos efeitos na saúde humana, o Comitê Científico da Toxicidade, Ecotoxicidade e Ambiente ${ }^{39}$ concluiu que há relação entre alguns desreguladores endócrinos e alterações na saúde humana, como o câncer de testículo, de mama e de próstata, o declínio das taxas de espermatozóides, deformidades dos órgãos reprodutivos e disfunção da tiróide.

Os esteróides podem, em alguns casos, estar envolvidos na iniciação de um tumor e induzirem eventos críticos na "progressão" maligna destes cânceres ${ }^{134}$. Alguns tipos de câncer podem estar ligados à exposição inadequada e/ou prolongada a hormônios endógenos ou substâncias estrogênicas. A proliferação celular aumenta devido à indução de estrogênios, o que leva ao aumento da probabilidade de ocorrerem mutações durante a síntese de DNA.

$\mathrm{O}$ desenvolvimento e as funções do sistema reprodutivo feminino dependem do balanço e das concentrações dos hormônios (estrogênios, andrógenos e tireoidianos), assim, uma disfunção no sistema endócrino pode resultar em algumas anomalias, tais como, irregularidades no ciclo menstrual, prejuízos na fertilidade, endometriose e ovários policísticos ${ }^{135}$.

Sabe-se que os desreguladores endócrinos têm a capacidade de modular ou alterar a intensidade dos hormônios, no entanto, resta saber se essas substâncias podem realmente afetar as funções do sistema reprodutivo feminino. Contudo, alguns fatos demonstram que isso pode realmente ocorrer, como por ex., o uso de DES em mulheres grávidas na década de 70 e no desenvolvimento de anomalias no sistema reprodutivo feminino de meninas nascidas de mães que fizeram uso desse medicamento, tais como, câncer vaginal, gravidez anormal e redução na fertilidade. Este fato é, sem dúvida, uma evidência dos efeitos à exposição aos desreguladores endócrinos.

Vários grupos de pesquisas acreditam que grande parte da população sofre com o decréscimo na qualidade do sêmen nas últimas décadas. De 1973 a 1992, Auger et al. ${ }^{136}$ analisaram a qualidade do sêmen de um grupo de homens férteis saudáveis, levando em conta o volume do fluido seminal, a concentração de esperma e a mobilidade e morfologia dos espermatozóides. Os autores observaram um declínio na concentração e mobilidade dos espermas nos homens por um período de 20 anos, e esse decréscimo da qualidade do sêmen coincide um aumento na incidência de anomalias no sistema reprodutivo masculino, incluindo câncer testicular. O aumento da incidência de câncer testicular também tem sido relatado por outros autores ${ }^{133}$.

Apesar de alguns pesquisadores sugerirem que pode não haver relação entre a exposição aos desreguladores endócrinos e alguns efeitos danosos em humanos, tal como a incidência de câncer de mama ${ }^{22,137}$, revisões indicam que há claras evidências experimentais e epidemiológicas do papel dessas substâncias na disfunção no sistema reprodutivo humano ${ }^{133-135,138}$.

\section{Efeitos em fetos ou espécies jovens}

Durante estágios prematuros da vida, na fase fetal e no desenvolvimento jovem, os hormônios são os principais responsáveis pelo controle e desenvolvimento de alguns tecidos e órgãos, incluindo os sistemas reprodutivo, imunológico e nervoso. As crianças e animais jovens são as espécies que apresentam os maiores riscos quando expostos aos desreguladores endócrinos, pois, durante este estágio crítico de desenvolvimento, desequilíbrios hormonais podem acarretar problemas que podem ser pronunciados mais tarde $\mathrm{e}^{133,139}$. Como o desenvolvimento dos sistemas reprodutivos feminino e masculino ocorre na fase fetal, as anomalias podem estar relacionadas ao aumento da exposição de substâncias estrogênicas in utero ${ }^{133}$.

Durante seu desenvolvimento, o feto é particularmente vulnerável a flutuações hormonais. A exposição a baixas concentrações de hormônios endógenos pode resultar em mudanças fisiológicas permanentes, que não são observadas em adultos quando expostos aos mesmos níveis ${ }^{139}$. A exposição a essas substâncias durante o desenvolvimento embrionário pode induzir tanto efeitos catastróficos (mortalidade e câncer) quanto efeitos sutis (mudança nas funções das enzimas), que são capazes de desorganizar a diferenciação das células e órgãos ${ }^{3}$.

Algumas disfunções sexuais são verificadas em recém-nascidos cujas mães tiveram contato com substâncias suspeitas de serem desreguladores endócrinos. Alguns efeitos relatados dessas substâncias podem afetar não só os indivíduos expostos, como também a população ou (sub) população a que pertencem, pelos efeitos propagados na sua descendência.

Alguns pesquisadores acreditam que as evidências da relação dos desreguladores endócrinos são ainda pequenas ou não existem. Entretanto, como podemos observar pelo número de publicações, os efeitos danosos à saúde humana e de numerosas espécies de animais são um fato. Podemos citar a exposição ao DDT e DDE dos jacarés na Flórida, que desenvolveram anomalias no sistema reprodutivo $^{3}$ e o desenvolvimento de anomalias no sistema reprodutivo de mulheres que foram expostas in utero ao $\mathrm{DES}^{2}$. 


\section{MÉTODOS ANALÍTICOS UTILIZADOS NA DETERMINAÇÃO DE FÁRMACOS E ESTROGÊNIOS EM MATRIZES AMBIENTAIS}

As técnicas analíticas utilizadas no monitoramento e identificação de micropoluentes no meio ambiente é importante tópico da química analítica. Métodos que determinam com acurácia essas substâncias em concentrações na faixa de $\mu \mathrm{g} \mathrm{L}^{-1}$ e ng L $\mathrm{L}^{-1}$ em matrizes ambientais complexas, tais como, águas naturais, solo, sedimentos, lodo biológico e efluente de ETE, são um desafio para muitos pesquisadores.

Para determinação de desreguladores endócrinos, em particular os estrogênios, diferentes métodos analíticos são relatados na literatura, os quais primeiramente foram validados para matrizes biológicas como sangue, tecido e urina ${ }^{140,141}$, sendo que algumas modificações nestes métodos algumas vezes são suficientes para amostras ambientais.

Nos últimos anos, foram publicados muitos métodos para a análise desses micropoluentes em amostras ambientais. Ternes ${ }^{142} \mathrm{fez}$ uma revisão de todos os métodos analíticos utilizados na determinação de estrogênios, a níveis de $\mathrm{ng} \mathrm{L}^{-1}$, em diferentes matrizes ambientais aquosas. No estudo de Petrovic et al. ${ }^{143}$ foi apresentada uma revisão de métodos analíticos usados na detecção de desreguladores endócrinos (alquilfenóis, PCDD, PCDF, bisfenol A, ftalatos, PBDE e estrogênios) em amostras ambientais, tais como, águas superficiais e subterrâneas, sedimentos, solo e lodo biológico.

Na determinação de estrogênios e outros DE em amostras aquosas, os métodos analíticos publicados são freqüentemente baseados na extração por fase sólida (EFS), derivatização e detecção por CG/EM, CG/EM/EM ou CLAE/EM. A EFS é uma técnica de extração simples, rápida e que requer pequenas quantidades de solventes. Freqüientemente são usados cartuchos ou discos de extração, comercialmente disponíveis, com uma variedade de adsorventes, tais como, $\mathrm{C}_{18}$, resina de copolímero poliestireno (ENV), sílica, alumina B, CN. A EFS não é só uma técnica de extração, mas também de concentração dos componentes.

A presença desses micropoluentes em outros tipos de amostras ambientais, tais como, lodo biológico e sedimentos, dita a necessidade do desenvolvimento de técnicas, que muitas vezes necessitam de etapas de extração com solvente, purificação (normalmente com sílica gel), cromatografia de permeação em gel e/ou EFS dos componentes antes de serem analisados em técnicas cromatográficas como CG/EM, CG/EM-EM ou CLAE/EM ${ }^{10,91,144}$.

A literatura também relata o uso de técnicas biológicas na identificação e quantificação de estrogênios naturais e sintéticos, tais como, ensaios de imunoadsorção enzimática (ELISA) e radioimunoensaio (RIE) ${ }^{2,124,145}$. O ensaio ELISA, que é baseado no uso de antígenos, tem sido descrito como um método altamente sensível e seletivo para análise de estrogênio e outros desreguladores endócrinos em ambientes aquáticos. O ensaio ELISA é usado em conjunto com técnicas de extração, como EFS, para aumentar seu limite de detecção. Recentemente, estão sendo desenvolvidos outros métodos analíticos baseados em imunoensaios para monitorar estrogênios e pesticidas em amostras de água, tal como um biossensor óptico ${ }^{146}$.

\section{TRATAMENTOS APLICADOS NA REMOÇÃO DE DESREGULADORES ENDÓCRINOS EM SISTEMAS AQUOSOS}

Atualmente, a presença de micropoluentes na água que podem causar danos à saúde humana e de animais é uma preocupação mundial. Tecnologias de tratamentos que podem eficientemente remover esses poluentes têm sido bastante investigadas. No entanto, não só sua eliminação, mas também a destruição do seu efeito potencial deve ser alcançada.

Uma avaliação da eficiência de remoção desses poluentes pelos processos de tratamento empregados nas plantas de tratamento de água potável e de esgoto doméstico é necessária. Estudos mostram que esses micropoluentes não são completamente removidos pelos processos convencionais de tratamento empregados nessas estações. Assim, outros processos de tratamento estão sendo investigados.

Novos processos de tratamento de efluentes devem ser desenvolvidos, visando um baixo nível de descarte de poluentes. Neste sentido, os processos oxidativos vêm ganhando atenção no tratamento de efluentes industriais e domésticos, bem como no tratamento de água potável ${ }^{147-149}$. Recentes estudos mostram que os processos oxidativos, tais como, ozonização e os POA são tecnologias promissoras na remoção desses micropoluentes no tratamento de água potável ou de outros sistemas aquosos. Outros tratamentos também foram investigados na remoção de desreguladores endócrinos em sistemas aquosos, como, filtração em carvão ativado, processos com membranas de nanofiltração (NF) e osmose reversa (OR), cloração, entre outros.

A ozonização tem sido considerada como uma tecnologia promissora na remoção de estrogênios naturais e sintéticos de água potável e efluentes de ETE ${ }^{13-15,150,151}$. Esses estudos indicam que os estrogênios são rapidamente oxidados com as baixas doses de ozônio que são usadas em estações de tratamento de água potável, alcançando altas remoções (> 97\%). Contudo, em alguns estudos, apesar da atividade estrogênica ter diminuído consideravelmente, uma estrogenicidade residual permaneceu, provavelmente, devido aos subprodutos de oxidação.

O sistema de filtro biológico em conjunto com o óxido de manganês $\left(\mathrm{MnO}_{2}\right)$ foi empregado na oxidação de desreguladores

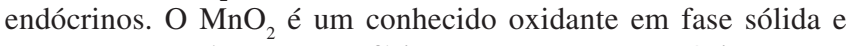
suas reações redox na superfície com compostos orgânicos estão sendo estudadas ${ }^{152}$. Neste sistema biocatalítico, o $\mathrm{MnO}_{2}$ e as bactérias que oxidam o manganês são integrados. $\mathrm{O} \mathrm{MnO}_{2}$ oxida os micropoluentes em moléculas menores, que junto com o $\mathrm{Mn}^{2+}$ são degradados biologicamente e o manganês reoxidado é redepositado no $\mathrm{MnO}_{2}$. Com esse sistema de tratamento, Rudder et al. ${ }^{152}$ alcançou a remoção de $81,7 \%$ de atividade estrogênica do $17 \alpha$-etinilestradiol em solução aquosa.

Os POA investigados na remoção de desreguladores endócrinos de ambientes aquáticos são: $\mathrm{O}_{3} / \mathrm{H}_{2} \mathrm{O}_{2}$, fotocatálise, $\mathrm{H}_{2} \mathrm{O}_{2} / \mathrm{UV}$. Sob condições de tratamento reais, pesticidas (atrazina e outros herbicidas) foram oxidados com $\mathrm{O}_{3} / \mathrm{H}_{2} \mathrm{O}_{2}$ e o Reativo de Fenton $\left(\mathrm{Fe}^{2+} / \mathrm{H}_{2} \mathrm{O}_{2}\right)^{153}$. A fotocatálise com $\mathrm{TiO}_{2}$ tem sido bastante estudada na degradação de estrogênios (17 $\beta$-estradiol, estrona) e outros DE (bisfenol A) $)^{154-159}$ alcançando boas remoções dos poluentes.

O carvão ativado é comumente usado no tratamento de água potável para remoção de micropoluentes. Alguns autores investigaram o uso de processos de filtração com carvão ativado na remoção dos DE, tais como, 17 $\beta$-estradiol, bisfenol A e $17 \alpha$-etinilestradiol ${ }^{160,161}$. Os resultados mostraram que são alcançadas remoções (> 99\%) em baixíssimas concentrações iniciais do poluente. Outros adsorventes também foram investigados ${ }^{162}$.

A US.EPA ${ }^{163}$ realizou um estudo para avaliar quais processos usados no tratamento de água podem ser usados para remoção de alguns DE. Concluiu que a melhor tecnologia disponível no tratamento de água para remoção de pesticidas (ex. metoxicloro, endosulfano e DDT), ftalatos (ex. DEHP e DEP), alquilfenóis e alquilfenóis etoxilados (ex. nonilfenol) e PCB é o processo de filtração em CAG (Carvão Ativado Granular). 
A aplicação de processos com membranas de nanofiltração (NF) e osmose reversa (OR) em plantas de tratamento de água aumentou significativamente ${ }^{164}$. Processos de NF e OR são particularmente efetivos na remoção de micropoluentes inorgânicos (tais como, nitrato, arsênico e flúor) e orgânicos (tais como, pesticidas, estrogênios entre outros) ${ }^{164-166}$.

É de suma importância avaliar se os tratamentos que removem efetivamente esses micropoluentes da água potável ou efluente de ETE são capazes de eliminar totalmente os efeitos deletérios que esses poluentes possam ter. Atualmente, alguns pesquisadores começaram a avaliar esse outro parâmetro, tão importante quanto a remoção dos poluentes.

A literatura relata que a atividade estrogênica de alguns DE é reduzida consideravelmente com alguns tratamentos, tais como, ozonização, cloração, fotocatálise, fotólise e um tratamento com enzimas ligninolíticas ${ }^{150,151,158,167-169}$, contudo, é relatada a permanência de um residual de atividade estrogênica no final de alguns tratamentos.

\section{CONCLUSÃO}

Muitas pesquisas vêm sendo realizadas com o objetivo de detectar os DE no meio ambiente, quer em águas, efluentes ou mesmo em solos e sedimentos. Observa-se que um grande esforço vem sendo realizado no sentido de se determinar quais substâncias podem ser classificadas como DE e, principalmente, se conhecer quais as concentrações que não provocam os efeitos relatados.

Um grande desenvolvimento é observado na área de identificação e quantificação dessas substâncias nas complexas matrizes ambientais, pois essas substâncias, suspeitas de causarem efeitos no sistema endócrino, são encontradas em concentrações realmente muito baixas.

Essas substâncias vêm sendo identificadas e monitoradas em diversos países, no entanto, poucos estudos foram realizados nos corpos hídricos, nas estações de tratamento de efluentes e nas águas de abastecimento do nosso país.

\section{REFERÊNCIAS}

1. European Workshop on Endocrine Disrupters, European ED workshop, Aronsborg (Balsa) Sweden, 2001.

2. Birkett, J. W.; Lester, J. N.; Endocrine Disrupters in Wastewater and Sludge Treatment Process, $1^{\text {st }}$ ed., Lewis Publishers, 2003.

3. Guillette, L. J. J.; Pickford, D. B.; Crain, D. A.; Rooney, A. A.; Percival, H. F.; Gen. Comp. Endocrinol. 1996, 101, 32.

4. Carlsen, E.; Giwercman, A.; Keiding, N.; Skakkebaek, N.; British Medical J. 1992, 305, 609.

5. Clara, M.; Strenn, B.; Saracevic, E.; Kreuzinger, N.; Chemosphere 2004, 56, 843.

6. Colucci, M. E.; Bork, H.; Topp, E.; J. Environ. Qual. 2001, 30, 2070.

7. Colucci, M. S.; Topp, E.; J. Environ. Qual. 2001, 30, 2077.

8. Lai, K. M.; Johnson, K. L.; Scrimshaw, M. D.; Lester, J. N.; Environ. Sci. Technol. 2000, 34, 3890.

9. Legler, J.; Dennekamp, M.; Vethaak, A. D.; Brouwer, A.; Koeman, J. H.; van der Burg, B.; Murk, A. J.; Sci. Total Environ. 2002, 293, 69.

10. Petrovic, M.; Eljarrat, E.; Lopez De Alda, M. J.; Barceló, D.; Trends Anal. Chem. 2001, 20, 637.

11. Ternes, T. A.; Stumpf, M.; Mueller, J.; Haberes, K.; Wilken, R.-D.; Servo, M.; Sci. Total Environ. 1999, 225, 81.

12. Ternes, T. A.; Kreckel, P.; Mueller, J.; Sci. Total Environ. 1999, $225,91$.

13. Bila, D. M.; Montalvão, A. F.; Dezotti, M.; $17^{\text {th }}$ World Ozone Congress, Strasbourg, França, 2005.

14. Ternes, T. A.; Stübera, J.; Herrmanna, N.; McDowella, D.; Ried, A.; Kampmann, M.; Teiser, B.; Water Res. 2003, 37, 1976.

15. Huber, M.; Canonica, S.; Park, G.-Y.; Von Guten, U.; Environ. Sci. Technol. 2003, 37, 1016.

16. US.EPA, 1997; Special Report on Environmental Endocrine Disruption: An Effects Assessment and Analisys, U.S. Environmental Protection Agency, Report No. EPA/630/R-96/012, Washington D. C, 1997.
17. CEC - Commission of the European communities. Community strategy for endocrine disrupters: a range of substances suspected of interfering with the hormone systems of humans and wildlife. Communication from the commission to the council and the European parliament, Brussels, COM(1999) 706 final, 1999.

18. ACSH, 1999; Endocrine Disrupters: A Scientific Perspective, American Council on Science and Health: New York, 1999.

19. Zacharewski, T. ; Environ. Sci. Technol. 1997, 31, 613.

20. Desbrow, C.; Routledge, E. J.; Brighty, G. C.; Sumpter, J. P.; Waldock, M.; Environ. Sci. Technol. 1998, 32, 1549.

21. Nogueira, J. M. F.; Química 2003, 88, 65.

22. Safe, S. H.; Toxicology 2004, 205, 3.

23. Soto, A. M.; Sonnenschein, C.; Chung, K. L.; Fernandez, M. F.; Olea, N.; Serrano F. O.; Environ. Health Perspect. 1995, 103, 113.

24. Gray, L. E. J.; Kelce, W. R.; Wiese, T.; Tyl, R.; Cook, J.; Klimefelter, G.; Desaulniers, D.; Wilson, E.; Zacharewski, T.; Waller, C.; Foster, P.; Laskey, J.; Reel, J.; Giesy, J.; Laws, S.; McLachlan, J.; Breslin, W.; Cooper, R.; Di Giulio, R.; Johnson, R.; Purdy, R.; Mihaich, E.; Safe, S.; Sonnenschein, C.; Welshons, W.; Miller, R.; McMaster, S.; Colborn, T.; Reprod. Toxicol. 1997, 11, 719 .

25. Allen, E.; Doisy, E. A.; J. Am. Med. Assoc. 1923, 81, 819.

26. Dodds, E. C.; Goldberg, L.; Lawson, W.; Robinson, R.; Nature 1938, 141, 247.

27. Safe, S. H.; Environ. Health Perspect. 2000, 108, 487.

28. Colborn, T.; Vom Saal, F. S.; Soto, A. M.; Environ. Health Perspect. 1993, $101,378$.

29. Fernandez, M. A.; Limaverde, A. M.; Castro, I. B.; Almeida, A. C. M.; Wagener, A. L. R.; Cad. Saúde Pública 2002, 18, 463.

30. Koifman, S.; Koifman, R. J.; Meyer, A.; Cad. Saúde Pública 2002, $18,435$.

31. Torres, J. P. M.; Malm, O.; Vieira, E. D. R.; Japenga, J.; Koopmans, G. F.; Cad. Saúde Pública 2002, 18, 477.

32. UBA TEXTE, 1996; Endocrinically Active Chemicals in the Environment, Biochemical Ecotoxicology Division, Arthur-Scheunert-Aller, 114, 14558 Bergholz-rehbrucke, Germany, USB Texte 3/96, 1996.

33. Kavlock, R. J.; Daston, G. P.; Derosa, C.; Fenner-Crisp, P.; Gray, L. E.; Kaattari, S.; Lucier, G.; Luster, M.; Mac, M. J.; Maczka, C.; Miller, R.; Moore, J.; Rolland, R.; Scott, G.; Sheehan, D. M.; Sinks, T.; Tilson, H. A.; Environ. Health Perspect. 1996, 104, 715.

34. Toppari, J.; Larsen, P.; Christiansen, P.; Giwercman, A.; Grandjean, P.; Guillette Jr, L. J.; Jégou, B.; Jensen, T. K.; Jouannet, P.; Keiding, N.; Leffers, H.; McLachlan, J. A.; Meyer, O.; Müller, J.; Meyts, E. R.-D.; Scheike, T.; Sharpe, R.; Sumpter, J.; Skakkebæk1, N. E.; Environ. Health Perspect. 1996, 104, 741.

35. Ankley, G. T.; Johnson, R. D.; Toth, G.; Folmar, L. C.; Detenbeck, N. E.; Bradbury, S. P.; Revs. Toxicol. Ser. B: Environ. Toxicol. 1997, 1, 1.

36. http://www.epa.gov/scipoly/oscpendo/edsparchive/103196mtgsum.htm, acessada em Junho 2005.

37. EDSTAC; Endocrine Disruptor Screening and Testing Advisory Committee - Final Report. EPA, 1998.

38. OECD; The Second Meeting of the OECD Validation Management Group (VMG) for the Screening and Testing of Endocrine Disrupters, Organisation for Economic Co-operation and Development (OECD), Paris, 2000.

39. CSTEE; Human and Wildlife Health Effects of Endocrine Disrupting Chemicals, with Emphasis on Wildlife and on Ecotoxicology Test Methods, Committee on Toxicity, Ecotoxicity and the Environment, (CSTEE), 1999.

40. CEC - Commission of the European communities. On the implementation of the Community strategy for endocrine disrupters - a range of substances suspected of interfering with the hormone systems of humans and wildlife. Communication from the commission to the council and the European parliament, Brussels, COM(2001) 262 final, 2001.

41. COMPREHEND; Community Programme Of Research on Endocrine Disrupters And Environmental Hormones, ENV4-CT98-0798, 2002.

42. OECD; Detailed Review Paper - Appraisal of Test Methods for Sex Hormone Disrupting Chemicals, Organisation for Economic Co-operation and Development (OECD), Paris, ENV/JM/MONO(2002)8, 2002.

43. IPCS; Global Assessment of the :State-of- the -Science of Endocrine Disrupors, International Programme on Chemical Safety Report WHO/ PCS/EDC/02.2, World Health Organization (WHO), Geneva, Switzerland; Damstra, T.; Barlow, S.; Bergmna, A.; Kavlock, R.; Van Der Kraak, G., eds.; 2002.

44. IEH; Information Exchange and International Co-ordination on Endocrine Disrupters, Report for DG Environment, European Commission, IEH Ref. No 3/9/7, 2003.

45. CEC - Commission of the European communities. On the implementation of the Community strategy for endocrine disrupters - a range of substances suspected of interfering with the hormone systems of humans and wildlife. Communication from the commission to the council and the European parliament, Brussels, SEC(2004) 1372, 2004. 
46. WRc-NSF Ref: UC 6052; Study on the Scientific Evaluation of 12 Substances in the Context of Endocrine Disrupter Priority List of Actions, European Commission, 2002

47. Santodonato, J.; Chemosphere 1997, 34, 835.

48. Louie, P. K. K.; Sin, D. W.-M.; Chemosphere 2003, 52, 1397.

49. Hutchins, S. R.; Ward, C. H.; J. Hydrology 1984, 67, 223.

50. Fromme, H.; Küchler, T.; Otto, T.; Pilz, K.; Muller, J.; Wenzel, A.; Water Res. 2002, 36, 1429.

51. Routledge, E. J.; Sumpter, J. P.; Environ. Toxicol. Chem. 1996, 15, 241.

52. Solé, M.; Lopez De Alda, M.; Castillo, M.; Porte, C.; Ladegaard-Pedersen, K.; Barceló D.; Environ. Sci. Technol. 2000, 34, 5076.

53. Kuch, H. M.; Ballschmiter, K.; Environ. Sci. Technol. 2002, 35, 3201.

54. Jobling, S.; Sumpter, J. P.; Aquat. Toxicol. 1993, 27, 361.

55. Biles, J. E.; Mcneal, T. P.; Begley, T. H.; Hollifield, H. C.; J. Agric. Food Chem. 1997, 45, 3541.

56. Fürhacker, M.; Scharf, S.; Weber, H.; Chemosphere 2000, 41, 751.

57. Fromme, H.; Pilz, K.; Müller, J.; Wenzel, A.; Water Res. 2002, 36, 1429.

58. Beresford, N.; Routledge, E. J.; Harris, C. A.; Sumpter, J. P.; Toxicol. Appl. Pharmacol. 2000, 162, 22

59. De Boever, P.; Demaré, W.; Vanderperren, E.; Cooreman, K.; Bossier, P; Verstraete, W.; Environ. Health Perspect. 2001, 109, 691.

60. Gaido, K. W.; Leonard, L. S.; Lovell, S.; Gould, J. C.; Babai, D.; Portier, C. J.; Mcdonnell, D. P.; Toxicol. Appl. Pharmacol. 1997, 143, 205.

61. Reys, L. L.; RFML Série III 2001, 6, 213

62. Beausse, J.; Trends Anal. Chem. 2004, 23, 753.

63. Lintelman, J.; Katayama, A.; Kurihara, N.; Shore, L.; Wenzel, A.; Pure Appl. Chem. 2003, 75, 631.

64. Fossi, M. C.; Casini, S.; Marsili, L.; Ancora, S.; Mori, G.; Néri, G.; Romeo, T.; Ausili, A.; Mar. Environ. Res. 2004, 48, 425.

65. Leblond, V. S.; Hontela, A.; Toxicol. Appl. Pharmacol. 1999, 157, 16.

66. Solé, M.; Raldua, D.; Barceló, D.; Porte, C.; Ecotoxicol. Environ. Saf. 2003, $56,373$.

67. Belfroid, A. C.; Van Der Horst, A.; Vethaak, A. D.; Schafer, A. J.; Rijs, G. B. J.; Wegener, J.; Cofino, W. P.; Sci. Total Environ. 1999, 225, 101.

68. Lopéz de Alda, M. J.; Barcelo, D.; J. Chromatogr., A 2001, 911, 203.

69. Hartmann, S.; Lacorn, M.; Steinhart, H.; Food Chem. 1998, 62, 7.

70. Peterson, E. W.; Davis, R. K.; Orndorff, H. A.; J. Environ. Qual. 2000, $29,826$.

71. Wilkinson, C. F.; Lamb, J. C.; Regul. Toxicol. Pharmacol. 1999, 30, 140.

72. Kuo, H.-W.; Din, W.-D.; J. Chromatogr., A 2004, 1027, 67.

73. Earls, A. O.; Axford, I. P.; Braybrook, J. H.; J. Chromatogr., A 2003, 983, 237

74. Babich, M. A.; Chen, S.-B.; Greene, M. A.; Kiss, C. T.; Porter, W. K.; Smith, T. P.; Wind, M. L.; Zamula, W. W.; Regul. Toxicol. Pharmacol. 2004, $40,151$.

75. Rudel, R. A.; Camann, D. E.; Spengler, J. D.; Korn, L. R.; Brody, J. G.; Environ. Sci. Technol. 2003, 37, 4543.

76. Behnisch, P. A.; Fujii, K.; Shiozaki, K.; Kawakami, I.; Sakai, S.-I.; Chemosphere 2001, 43, 977.

77. Casey, F. X. M.; Larsen, G. L.; Hakk, H.; Siri, S.; Environ. Sci. Technol. 2003, 37, 2400.

78. Jobling, S.; Nolan, M.; Tyler, C. R.; Brighty, G.; Sumpter, J. P.; Environ Sci. Technol. 1998, 32, 2498.

79. Pawlowski, A.; Ternes, T. A.; Bonerz, M.; Kluczka, T.; van der Burg, B.; Nau, H.; Erdinger, L; Braunbeck, T.; Toxicol. Sci. 2003, 75, 57.

80. Pawlowski, A.; Ternes, T. A.; Bonerz, M.; Rastall, A. C.; Erdinger, L.; Braunbeck, T.; Toxicol. in Vitro 2004, 18, 129.

81. Svenson, B.; Allard, A.-S.;, Ek, M.; Water Res. 2003, 37, 4433.

82. Routledge, E. J.; Sheahan, D.; Desbrow, C.; Brighty, G.; Waldock, M.; Sumpter, J. P.; Environ. Sci. Technol. 1998, 32, 1559.

83. Rodger-Gray, T. P.; Jobling, S.; Kelly, C.; Morris, S.; Brighty, G.; Waldock, M.; Sumpter, J. P.; Tyler, C. R.; Environ. Sci. Technol. 2001, 35, 462.

84. Johnson, A. C.; Sumpter, J. P.; Environ. Sci. Technol. 2001, 35, 4697.

85. Johnson, A. C.; Belfroid, A.; Di Corcia, A.; Sci. Total Environ. 2000, 256, 163.

86. Boyd, G. R.; Reemtsma, H.; Grimmd. D. A.; Mitra, S.; Sci. Total Environ. 2003, 311, 135 .

87. Hohenblum, P.; Gans, O.; Moche, W.; Scharf, S.; Lorbeer, G.; Sci. Total Environ. 2004, 333, 185.

88. Kolpin, D. W.; Furlog, E. T.; Meyer, M. T.; Thurman, E. M.; Zaugg, S. D.; Barber, L. B.; Buxton, H. T.; Environ. Sci. Technol. 2002, 36, 1202.

89. Köger, C. S.; Teh, S. J.; Hinton, D. E.; Mar. Environ. Res. 2000, 50, 201.

90. Körner, W.; Bolz, U.; Sübmuth, W.; Hiller, G. G.; Schuller, W.; Hanf, V.; Hagenmaier, H.; Chemosphere 2000, 40, 1131.

91. Ternes, T. A.; Andersen, H.; Gilberg, D.; Bonerz, M.; Anal. Chem. 2001, 74,3498

92. Yamamoto, H.; Liljestrand, H. M.; Water Sci. Technol. 2003, 47, 77.

93. Laganà, A.; Bacaloni, A.; De Leva, I.; Faberi, A.; Fago, G.; Marino, A.; Anal. Chim. Acta 2004, 501, 79.
94. Azevedo, D. A.; Lacorteb, S.; Viana, P.; Barceló, D.; J. Braz. Chem. Soc. 2001, 12, 532

95. Cargouët, M.; Perdiz, D.; Mouatassim-Souali, A.; Tamisier-Karolak, S.; Levi, Y.; Sci. Total Environ. 2004, 324, 55.

96. Baronti, C.; Curini, R.; D‘Ascenzo, G.; Di Corcia, A.; Gentili, A.; Samperi, R.; Environ. Sci. Technol. 2000, 34, 5059.

97. Larsson, D. G. J.; Adolfsson-Erici, M.; Parkknen, J.; Pettersson, M.; Berg, A. H.; Olsson, P.-E.; Förlin, L.; Aquat. Toxicol. 1999, 45, 91.

98. Ternes, T. A.; Meisenheimer, M.; Mcdowell, D., Sacher, F.; Brauch, H.-J.; Haist-Gulde, B.; Zulei-Seibert, N.; Environ. Sci. Technol. 2002, 36, 3855.

99. Snyder, S. A.; Keith, T. L.; Verbrugge, D. A.; Snyder, E. A.; Gross, T. S.; Kannan, K.; Giesy, J. P.; Environ. Sci. Technol. 1999, 33, 2814.

100. Xiao, X.-Y.; Mccalley, D. V.; Mcevoy, J.; J. Chromatogr., A 2001, 923, 195.

101. Stumpf, M.; Ternes, T. A.; Wilken, R.-D.; Rodrigues, S. V.; Baumann, W.; Sci. Total Environ. 1999, 225, 135.

102. Goldman, J. M.; Laws, S. C.; Balchak, S. C.; Cooper, R. L.; Kavlock, R. J.; Crit. Rev. Toxicol. 2000, 30, 135.

103. Allen, V.; Matthiessen, P.; Scott, A. P.; Haworth, S.; Feist, S.; Thain, J. E.; Sci. Total Environ. 1999, 233, 5.

104. Robinson, C. D.; Brown, E.; Craf, J. A.; Davies, I. M.; Davies, I. M.; Moffat, C. F.; Pirie, D.; Robertson, F.; Stagg, R. M.; Struthers, S.; Aquat. Toxicol. 2002, 62, 119.

105. Rodger-Gray, T. P.; Jobling, S.; Morris, S.; Morris, S.; Brighty, G.; Waldock, M. J.; Sumpter, J. P.; Tyler, H. R.; Environ. Sci. Technol. 2000, $34,1521$.

106. Solé, M.; Porte, C.; Barcelo, D.; Trends Anal. Chem. 2001, 20, 518.

107. Panter, G. H.; Thompson, R. S.; Sumpter, J. P.; Aquat. Toxicol. 1998, 42, 243.

108. Knörr, S.; Braunbeck, T.; Ecotoxicol. Environ. Saf. 2002, 51, 187.

109. Panter, G. H.; Thompson, R. S.; Sumpter, J. P.; Environ. Sci. Technol. 2000, $34,2756$.

110. Hartley, W. R.; Thiyagarajah, A.; Andersen, M. B.; Broxson, M. W.; Major, S. E.; Zell, S. I.; Mar. Environ. Res. 1998, 46, 145.

111. Kang, I. J.; Yokota, H.; Oshima, Y.; Tsuruda, Y.; Yamaguchi, T.; Maeda, M.; Imada, N.; Tadokoro, H.; Honjo, T.; Chemosphere 2002, 47, 71.

112. Shioda, T.; Wakabayashi, M.; Chemosphere 2000, 40, 239.

113. Moncaut, N.; Nostro, F. L.; Maggese, M C.; Aquat. Toxicol. 2003, 63, 127.

114. Rose, J.; Holbech, H.; Lindholst, C.; Norum, U.; Povlsen, A.; Korsgaard, B.; Bjerregaard, P.; Comp. Biochem. Physiol., Part C: Toxicol. Pharmacol. 2002, 131, 531.

115. Schmid, T.; Gonzalez-Valero, J.; Rufli, H.; Dietrich, D. R.; Toxicol. Lett. 2002, 131, 65 .

116. Folmar, L. C.; Hemmer, M.; Hemmer, R.; Bowman, C.; Kroll, K.; Denslow, N. D.; Aquat. Toxicol. 2000, 49, 77.

117. Gimeno, S.; Komen, H.; Gerritsen, A. G.; Bowmer, T.; Aquat. Toxicol. 1998, 43, 77 .

118. Markey, C. M.; Rubin, B.; S.; Soto, A. M.; Sonnenschein, C.; J. Steroid Biochem. Mol. Biol. 2003, 1802, 1.

119. Aguilar, A.; Borrell, A.; Sci. Total Environ. 1994, 154, 237.

120. Bitman, J.; Cecil, H. C.; Harris, S. J.; Fries, G.; Science 1968, 162, 371

121. Guillette, L. J. J.; Woodward, A. R.; Crain, A. D.; Pickford, D. B.; Rooney, A. A.; Percival, H. F.; Gen. Comp. Endocrinol. 1999, 116, 356.

122. Milnes, M. R.; Woodward, A. R.; Rooney, A. A.; Rooney, A. A.; Guillette, L. J.; Comp. Biochem. Physiol., Part A: Mol. Integr. Physiol. 2002, 131, 923.

123. Gagné, F.; Blaise, C.; Salazar, M.; Salazar, S.; Hansen, P. D.; Comp. Biochem. Physiol., Part C: Toxicol. Pharmacol. 2001, 128, 213.

124. Irwin, L. K.; Gray, S.; Oberdörster, E.; Aquat. Toxicol. 2001, 55, 49.

125. Fry, D. M.; Environ. Health Perspect. 1995, 103, 165.

126. Fry, D. M.; Tonne, C. K.; Science 1981, 213, 922

127. Dalton, R. B.; Nature 2002, 416, 665.

128. Bögi, C.; Schwaiger, J.; Ferling, H.; Mallow, U.; Steineck, C.; Sinowatz, F.; Kalbfus, W.; Negele, R. D.; Lutz, I.; Kloasa,W.; Environ. Res. 2003, 93, 195.

129. Thompson, S.; Tilton, F.; Schlenk, D.; Benson, W. H.; Mar. Environ. Res. 2000, 51, 185.

130. Janssen, P. A. H.; Lambert, J. G. D.; Vethaak, A. D.; Goos, H. J. Th.; Aquat. Toxicol. 1997, 39, 195.

131. Daston, G. P.; Gooch, J. W.; Breslin, W. J.; Shuey, D. L.; Nikiforov, A. I.; Fico, T. A.; Gorsuch, J. W.; Reproduct. Toxicol. 1997, 11, 465.

132. Harrison, P. T. C.; Holmes, P.; Humfrey, C. D. N.; Sci. Total Environ. 1997, 205, 97.

133. Weber, R. F. A.; Pierik, F. H.; Dohlr, G. R.; Burdorf, A.; BJU Int. 2002, $89,143$.

134. Dickson, R. B.; Lippman, M. E.; Tips 1986, 294.

135. Nicolopoulou-Stamati, P.; Pitsos, M. A.; Hum. Reprod. Update 2001, 7, 323.

136. Auger, J.; Kunstmann, J. M.; Czyglik, F.; Pierre, J.; N. Engl. J. Med. 1995, $332,281$. 
137. Safe, S. H.; Environ. Health Perspect. 1995, 103, 346.

138. Davis, D. L.; Bradlow, J.; Wolff, M.; Woodruff, T.; Hoel, D. G.; AntonCulver, H.; Environ. Health Perspect. 1993, 101, 372.

139. Solomon, G. M.; Schettler, S.; Can. Med. Assoc. J. 2000, 163, 1471.

140. Hedenmo, M.; Eriksson, B.-M., J. Chromatogr., A 1995, 692, 161.

141. Whitlam, J. B.; Vine, J. H.; J. Chromatogr., B: Anal. Technol. Biomed. Life Sci. 1980, 181, 463.

142. Ternes, T. A.; Trends Anal. Chem. 2001, 20, 419.

143. Petrovic, M.; Eljarrat, E.; Lopez de Alda, M. J.; Barceló, D.; J. Chromatogr., A 2002, 974, 23

144. Kuster, M.; López de Alda, M. J.; Barceló, D.; Trends Anal. Chem. 2004, 23, 790 .

145. Li, Z.; Wang, S.; Lee, N. A.; Allan, R. D.; Kennedy, I. R.; Anal. Chim. Acta 2004, 503, 171.

146. Tschmelak, J.; Proll, G.; Gauglitz, G.; Talanta 2005; 65, 313.

147. Nogueira, R. F. P.; Jardim, W. F.; Quim. Nova 1998, 21, 69.

148. Freire, R. S.; Peligrine, R.; Kubota, L. T.; Duran, N.; Peralta-Zamora, P.; Quim. Nova 2000, 23, 504

149. Almeida, E.;Assalin, M. R.; Rosa, M. A.; Duran, N.; Quim. Nova 2004, $27,818$.

150. Alum, A.; Yoon, Y.; Westerhopff, P.; Abbaszadegan, M.; Environ. Toxicol. 2004, 19, 257.

151. Kim, S.-E.; Yamada, H.; Tsuno, H.; Ozone: Sci. Eng. 2004, 26, 563.

152. Rudder, J.; Van De Wielea, T.; Dhooge, W.; Comhaireb, F.; Verstraetea, W.; Water Res. 2004, 38, 184.

153. Ijeplaar, G. F.; Meijers, R. T.; Hopman, R.; Kruitof, J. C.; Ozone. Sci. Eng. 2000, 22, 607 .
154. Coleman, H. M.; Eggins, B. R.; Byrne, J. A.; Palmer, F. L.; King, E.; Appl. Catal., B 2000, 24, L1.

155. Coleman, H. M.; Routledge, E. J.; Sumpter, J. P.; Eggins, B. R.; Byrne, J. A.; Water Res. 2004, 38, 3233.

156. Nakashima, T.; Ohko, Y.; Tryk, D. A.; Fujishima, A.; J. Photochem. Photobiol., A 2002, 151, 207.

157. Nakashima, T.; Ohko, Y.; Kubota, Y.; Fujishima, A.; J. Photochem. Photobiol. 2003, 160, 115.

158. Ohko, Y.; Ando, I.; Niwa, C.; Tatsuma, T.; Yamamura, T.; Nakashima, T.; Kubota, Y.; Fujishima, A.; Environ. Sci. Technol. 2001, 35, 2365.

159. Ohko, Y.; Iuchi, K.-I.; Niwa, C.; Tatsuma, T.; Nakashima, T.; Iguchi, T.; Kubota, Y.; Environ. Sci. Technol. 2002, 36, 4175.

160. Füerhacker, M.; Dürauer, M.; Jungbauer, A.; Chemosphere 2001, 44, 1573.

161. Yoon, Y.; Westerhoff, P.; Snyder, S. A.; Hara, M.; Higuchi, A.; Water Res. 2003, 37, 3530

162. Zhang, Y.; Zhou, J. L.; Water Res. 2005, 39, 3991.

163. US.EPA; Removal of endocrine disruptor chemicals using drinking water treatment processes, EPA/625/R-00/012, Washington D.C., 2001.

164. Van Der Bruggen, B.; Vandecasteele, C.; Environ. Pollut. 2003, 122, 435.

165. Nghiem, L. D.; Manis, A.; Soldenhoff, K.; Schäfer, A. I.; J. Membr. Sci. 2004, 242, 37.

166. Van Der Bruggen, B.; Schaep, J.; Maes, W.; Wilms, D.; Vandecasteele, C.; Desalination 1998, 117, 139.

167. Coleman, H. M.; Abdullahb, M. I.; Eggins, B. R.; Palmer, F. L.; Appl. Catal., B 2005, 55, 23.

168. Huber, M.; Ternes, T. A.; Von Gunten, U.; Environ. Sci. Technol. 2004, 38, 5177. 169. Suzuki, K.; Hirai, H.; Murata, H.; Nishida, T.; Water Res. 2003, 37, 1972. 